\title{
Heterogeneity and Aggregation
}

\author{
Richard Blundell* and Thomas M. Stoker ${ }^{\dagger}$
}

November 2006

\begin{abstract}
This survey covers recent solutions to aggregation problems in three application areas, consumer demand analysis, consumption growth and wealth, and labor participation and wages. Each area involves treatment of heterogeneity and nonlinearity at the individual level. Three types of heterogeneity are highlighted: heterogeneity in individual tastes, heterogeneity in income and wealth risks and heterogeneity in market participation. Work in each area is illustrated using results from empirical data. The overall aim is to show how concerns faced by empirical researchers regarding aggregation can be addressed.
\end{abstract}

Acknowledgements: A previous version of this chapter was published in the Journal of Economic Literature, vol. 43, 2, pp. 347-391, We are grateful for comments from numerous colleagues, especially Orazio Attanazio, Martin Browning, Jim Heckman, Arthur Lewbel and the reviewers. Thanks are also due to Howard Reed and Zoe Oldfield who helped organise the data for us. Financial support from the ESRC Centre for the Micro-Economic Analysis of Fiscal Policy at IFS is gratefully acknowledged. The usual disclaimer applies.

\section{Introduction}

Different people do, in fact, behave differently. To describe the behavior of a group, one must come to grips with this heterogeneity. In terms of empirical research in economics, this means facing and resolving aggregation problems.

Aggregation problems are more than a cloying annoyance in empirical work. They exist at virtually every level, from the initial issues of data construction and model specification to the subsequent issues

\footnotetext{
${ }^{*}$ Institute for Fiscal Studies and Department of Economics, University College London, Gower Street, London, WC1E $6 \mathrm{BT}$.

† Sloan School of Management, Massachusetts Institute of Technology, 50 Memorial Drive, Cambridge, MA 02138 USA.
} 
of how to usefully summarize and apply results. Because of their broad reach, aggregation problems have traditionally been kept closeted within the practice of empirical work, along with other issues for which there are no simple answers. But recently, this is changing, as there has been substantial progress in dealing with aggregation problems in applied research. This survey covers much of this development.

At the outset we must address a basic question: why consider aggregation problems at all? One could take the view that economics is mainly about the behavior of individuals or of individual markets, and assert a methodological position that only analysis of such individuals or individual markets makes any real sense. However, such a view eliminates the applicability of the tenets of economic behavior to some of the most important questions in economics, namely those that concern economic aggregates. Economic policy is most often concerned with prices, interest rates, aggregate consumption and savings, market demand and supply, total tax revenues, aggregate wages, unemployment, and so forth. The valuation and allocation of scarce resources requires that attention be paid to large groups of individuals.

It is important to study relationships among economic aggregates, and to bring individual economic behavior to bear on those relationships. Addressing aggregation problems just means creating a bridge between those behaving individuals and the economic aggregates. After stating this goal, however, we immediately meet several vexing issues as to how to even start to think about linking 'individual' and 'aggregate.'

At one extreme are the almost philosophical issues of where, or at what level, to apply the strictures of economic theory. Are we to assume that regularities associated with rationality apply to entire economies, to 'reasonably homogeneous' groups of households, firms or other types of economic agents, or to Hicks' Mr. Brown or Mr. Jones, ${ }^{1}$ as well as any of our own relatives or neighbors. To assert that there is a 'correct' individual level at which to apply a mathematical model that is in line with rational behavior is to take a stand on those issues; a stand which could only be properly validated by experimentation or much more extensive empirical research than has been performed to date. ${ }^{2}$

\footnotetext{
${ }^{1}$ See $\operatorname{Hicks}(1956$, p. 55).

${ }^{2}$ This effort is underway, primarily in work on psychological tendencies in economics, finance and marketing. This work examines what is 'consistent economic behavior,' and whether departures from rational behavior are systematic or idiosyncratic.
} 
At the other extreme are questions pertaining to what the appropriate 'aggregate' is. One typically considers sums or averages as reported in national income accounts as the relevant aggregates. They are usually the most interpretable numbers, and the most relevant for pricing or policy analysis. But with large populations, one could consider many other kinds of aggregates, or statistics from the population. ${ }^{3}$

Once these issues are settled - what is the relevant "individual level" and what is the relevant "aggregate" - then aggregation problems become purely practical. For any application, a model must be specified which captures all important economic effects, allows for relevant individual heterogeneity, and bridges the gap between individual and aggregate, facilitating analysis at both levels.

This survey covers specific solutions and related work in primarily three application areas: consumer demand analysis, consumption and saving analysis and analysis of wages and labor market participation. A key issue is to identify what kinds of individual differences, or heterogeneity, are relevant for each application area. As an organizing principle, we consider (i) heterogeneity in individual tastes and incomes, (ii) heterogeneity in wealth and income risks faced by individuals and (iii) heterogeneity in market participation. ${ }^{4}$ There is a generic tension between the degree of individual heterogeneity accounted for and the ease with which one can draw implications for economic aggregates. We point out how different types of heterogeneity are accommodated in the different application areas.

Our approach is practical, and we hope to address many of the concerns faced by empirical research regarding aggregation. We take a "micro-econometric" view of the individual model - namely an econometric model (obeying restrictions of economic theory) is applicable to individuals or households. We consider model specifications that are typically used in empirical analysis of individual data, in each application area. We take the relevant "aggregates" to be either totalled or per-capita (averaged) values of the individual variables of interest, coinciding with aggregates as typically reported for regions or whole economies. Whether such aggregates are easy to model or not, they are the most interpretable,

\footnotetext{
${ }^{3}$ For instance, to study inequality, a relevant aggregate would be the Gini coefficient. The choice of aggregate may even be informed by empirical regularities in individual data. For example. if an individual model is best specified with the logarithm of observed income, the geometric mean of income might be a more natural aggregate than total income or average income.

${ }^{4}$ This roughly coincides with the categorization of heterogeniety discussed in Browning, Hansen and Heckman (1999, chapter 8).
} 
and the most useful types of aggregates for interpretation, policy analysis or other uses of empirical results.

We are concerned with models that strike a balance between realism (flexibility), adherence to restrictions from economic theory and connections between individual behavior and aggregate statistics. We consider several settings where individual models are intrinsically nonlinear, and for those we must make specific assumptions on the distributions of relevant heterogeneous characteristics. We present results that can be used to explore the impact of heterogeneity in empirical applications, that assume reasonable (and hopefully plausible) parametrizations of both individual equations and distributions of heterogeneity. We do not go into details about estimation; but for each application area we will present models with empirically plausible equations for individuals, and consistent equations for the relevant economic aggregates. The point is to have the ability to address empirical issues at the individual (micro) level, the aggregate (macro) level, or both.

We begin with our coverage of consumer demand models in Section 2, the area which has seen the most extensive development of solutions to aggregation problems. The difficult issues in consumer demand include clear evidence of nonlinearity in income effects (e.g. Engel's Law for food) and pervasive evidence of variations in demand with observable characteristics of households. We discuss each of these problems in turn, and use the discussion to cover traditional results as well as 'aggregation factors' as a method of empirically studying aggregation bias. We cover recent empirical demand models, and present aggregation factors computed from data on British households. That is, we cover the standard issues faced by aggregating over heterogeneous households in a static decision-making format, and illustrate with application to empirical demand models in current use. We close with a discussion of recent work that studies aggregate demand structure without making specific behavioral assumptions on individual demands.

In Section 3 we discuss models of overall consumption growth and wealth. Here we must consider heterogeneity in tastes, but we focus on the issues that arise from heterogeneity in income shocks, showing how different types of shocks transmit to aggregate consumption. We start with a discussion of quadratic preferences in order to focus on income and wealth, and then generalize to recent empirical models that permit precautionary saving. Because of the log-linear form of these models, we must 
make explicit distributional assumptions to solve for aggregate equations. We cover the types of heterogeneity found in consumption relationships, as well as various other aspects of our modeling, illustrating with empirical data. We follow this with a brief discussion of modeling liquidity constraints and the impacts on aggregate consumption. We close this section with a discussion of recent progress in general equilibrium modeling of consumption, saving and wealth.

Section 4 covers recent work on labor participation and aggregate wage rates. The main issues here concern how to interpret observed variations in aggregate wages - are they due to changes in wages of individuals or to changes in the population of participating workers? We focus on the issues of heterogeneity in market participation, and develop a paradigm that allows isolation of the participation structure from the wage structure. This involves tracking the impacts of selection on the composition of the working population, the impacts of weighting individual wage rates by hours in the construction of aggregate wages, and the impact of observed wage heterogeneity. We show how accounting for these features gives a substantively different picture of the wage situation in Britain than that suggested by observed aggregate wage patterns. Here we have a situation where there is substantial heterogeneity and substantial nonlinearity, and we show how to address these issues and draw conclusions relevant to economic policy.

Section 5 concludes with some general observations on the status of work on aggregation in economics.

This paper touches on many of the main ideas that arise in addressing aggregation problems, but it is by no means a comprehensive survey of all relevant topics or recent approaches to such problems. For instance, we limit our remarks on the basic nature of aggregation problems, or how it is senseless to ascribe behavioral interpretations to estimated relationships among aggregate data without a detailed treatment of the links between individual and aggregate levels. It is well known that convenient constructs such as a 'representative agent' have, in fact, no general justification, we will not further belabor their lack of foundation. See the surveys by Stoker (1993) and Browning, Hansen and Heckman (1998) for background on these basic problems. It is useful to mention two related lines of research, that we do not cover. The first is the work on how economic theory provides few restrictions on market excess demands - see Hugo Sonnenschein (1972) and Wayne Schafer and Sonnenschein (1982) among 
others, and Donald J. Brown and Rosa L. Matzkin (1996) for a recent contribution. The second is the work on collective decision making within households as pioneered by Pierre-Andre Chiappori (1988, 1994).

We will also limit our attention to aggregation over individuals, and not discuss the voluminous literature on aggregation over commodities. This latter literature concerns the construction of aggregate 'goods' from primary commodities, as well as the consistency of multistage budgeting and other simplifications of choice processes. While very important for empirical work, the issues of commodity aggregation apply within decision processes of individuals and, as such, would take us too far afield of our main themes. See the survey by Blundell (1988) as well as the book Blackorby, Primont and Russell (1978) for background on commodity aggregation and multistage budgeting. Moreover, we do not cover the growing literature on hedonic/characteristics models, which can serve to facilitate commodity aggregation or other simplifications in decision making.

Finally, we do not cover in great detail work that is associated with time series aggregation. That work studies how the time series properties of aggregate statistics relate to the time series processes of associated data series for individuals, such as stationarity, co-integration, etc. To permit such focus, that work relies on strictly linear models for individual agents, which again, turn the discussion away from heterogeneity in individual reactions and other behavior. We do make reference to time series properties of income processes as relevant to our discussion of individual and aggregate consumption, but do not focus on time series properties in any general way. Interested readers can pursue Granger (1980, 1987, 1990) and the book by Forni and Lippi (1997) for more comprehensive treatment of this literature. $^{5}$

\section{Consumer Demand Analysis}

We begin with a discussion of aggregation and consumer demand analysis. Here the empirical problem is to characterize budget allocation to several categories of commodities. The individual level is that of a household, which is traditional in demand analysis. The economic aggregates to be

\footnotetext{
${ }^{5}$ See Stoker (1986c, 1993) and Lewbel (1994) and others for examples of clear problems in inferring behavioral reactions from time series results in the presence of individual heterogeneity.
} 
modelled are average (economy-wide, per household) expenditures on the categories of commodities. We are interested in aggregate demand, or how average category expenditures relate to prices and the distribution of total budgets across the economy.

In a bit more detail, we assume that households have a two-stage planning process, where they set the total budget for the current period using a forward looking plan, and then allocate that current budget to the categories of non-durable commodities. ${ }^{6}$ As such, we are not concerned with heterogeneity in the risks faced by households in income and wealth levels - they have already been processed by the household in their choice of total budget (and, possibly, in their stocks of durable goods). We consider commodity categories that are sufficiently broad that household expenditures are non-zero (food categories, clothing categories, etc.), and so we are not concerned with zero responses, or heterogeneity in market participation.

We are concerned with heterogeneity in total budgets and in needs and tastes. It is a wellknown empirical fact that category expenditure allocations vary nonlinearly with total budget size (for instance, Engel's Law with regard to food expenditures). Early applications of exact aggregation demand systems had budget shares in semi-log form (with or without attributes), namely the popular Translog models of Jorgenson, Lau and Stoker $(1980,1982)$ and Almost Ideal models of Deaton and Muellbauer (1980a,b) respectively. More recent empirical studies have shown the need for further nonlinear terms in certain expenditure share equations. In particular, evidence suggests that quadratic logarithmic income terms are required (see, for example, Atkinson, Gomulka and Stern. (1990), Bierens and Pott-Buter (1990), Hausman, Newey and Powell (1994), Härdle, Hildenbrand and Jerison (1991), Lewbel (1991) and Blundell, Pashardes and Weber (1993)). This nonlinearity means that aggregate demands will be affected by total budget size as well as the degree of inequality in budgets across consumers. It is also well known that category expenditures vary substantially with demographic composition of households, such as how many children are present, or whether the head of household is young or elderly, see Barten A.P. (1964), Pollak and Wales (1981), Ray (1983) and Browning (1992).

Our aim is to understand how behavioral effects for households impinge on price effects and distrib-

\footnotetext{
${ }^{6}$ Provided that intertemporal preferences are additive, this accords with a fairly general intertemporal model of expected utility maximization (see Deaton and Muellbauer (1980b), among others).
} 
utional effects on aggregate demands. Understanding these effects is a key ingredient in understanding how the composition of the population affects demand growth over time and relative prices across the different commodity categories.

\subsection{Aggregation of Consumer Demand Relationships}

Our framework requires accounting for individuals (households), goods and time periods. In each period $t$, individual $i$ chooses demands $q_{i j t}$ (or equivalently, expenditures $p_{j t} q_{i j t}$ ) for $j=1, \ldots, J$ goods by maximizing preferences subject to an income constraint, where $i=1, \ldots, n_{t}$. Prices $p_{j t}$ are assumed to be constant across individuals at any point in time, with $p_{t}=\left(p_{1 t}, \ldots, p_{J t}\right)$ summarizing all prices. Individuals have total expenditure budget $m_{i t}=\sum_{j} p_{j t} q_{i j t}$, or income for short, ${ }^{7}$ and are described by a vector of household attributes $z_{i t}$, such as composition and demographic characteristics. The general form for individual demands is written

$$
q_{i j t}=g_{j t}\left(p_{t}, m_{i t}, z_{i t}\right)
$$

This model reflects heterogeneity in income $m_{i t}$ and individual attributes $z_{i t}$. Specific empirical models involve the specification of these elements, ${ }^{8}$ including a parametric formula for $g_{j t}$.

Economy-wide average demands and average income are

$$
\frac{\sum_{i} q_{i j t}}{n_{t}}, j=1, \ldots, J \text { and } \frac{\sum_{i} m_{i t}}{n_{t}}
$$

We assume that the population of the economy is sufficiently large to ignore sampling error, and represent these averages as the associated population means

$$
E_{t}\left(q_{i j t}\right), j=1, \ldots, J \text { and } E_{t}\left(m_{i t}\right)
$$

Our general framework will utilize various other aggregates, such as statistics on the distribution of

\footnotetext{
${ }^{7}$ It is common parlance in the demand literature to refer to 'total budget expenditure' as 'income,' as we do here. In the later section on consumption, we return to using 'income' more correctly, as current consumption expenditures plus savings.

${ }^{8}$ For most of our discussion, $z_{i t}$ can be taken as observable. When we discuss explicit empirical models, we will include unobserved attributes, random disturbances, etc.
} 
consumer characteristics $z_{i t}$.

\subsubsection{Various Approaches: Exact Aggregation and Distributional Restrictions}

We begin by discussing various approaches to aggregation in general terms. From (1), aggregate demand is given formally as

$$
E_{t}\left(q_{i j t}\right)=\int g_{j t}\left(p_{t}, m_{i t}, z_{i t}\right) d F_{t}\left(m_{i t}, z_{i t}\right)
$$

where $F_{t}\left(m_{i t}, z_{i t}\right)$ is the cross-section distribution of income and attributes at time $t$. At the simplest

level, approaches to aggregation seek a straightforward relationship between average demand, average income and average attribute values

$$
E_{t}\left(q_{i j t}\right)=G_{j t}\left(p_{t}, E_{t}\left(m_{i t}\right), E_{t}\left(z_{i t}\right)\right)
$$

The exact aggregation approach is based on linearity restrictions on individual preferences/demands $g_{i j t}$ that allow the relationship $G_{j t}$ to be derived in a particularly simple way, such that knowledge of $G_{j t}$ is sufficient to identify (the parameters of) the individual demand model. Take for example,

$$
g_{j t}\left(p_{t}, m_{i t}, z_{i t}\right)=b_{0 j}\left(p_{t}\right) m_{i t}+b_{1 j}\left(p_{t}\right) m_{i t} \ln m_{i t}+b_{2 j}\left(p_{t}\right) m_{i t} z_{i t}
$$

where we suppose $z_{i t}$ is a single variable that has $z_{i t}=1$ for an elderly household and $z_{i t}=0$ otherwise. Individual demand has a linear term in income, a nonlinear term in income, and the slope of the linear term is different for elderly households. All of these slopes can vary with $p_{t}$. Now, aggregate demand is

$$
E_{t}\left(q_{i j t}\right)=b_{0 j}\left(p_{t}\right) E_{t}\left(m_{i t}\right)+b_{1 j}\left(p_{t}\right) E\left(m_{i t} \ln m_{i t}\right)+b_{2 j}\left(p_{t}\right) E\left(m_{i t} z_{i t}\right),
$$

which depends on average income $E_{t}\left(m_{i t}\right)$ and two other statistics, $E\left(m_{i t} \ln m_{i t}\right)$ and $E\left(m_{i t} z_{i t}\right)$. The coefficients are the same in the individual and aggregate models, which is the bridge through which individual preference parameters manifest in aggregate demands (and can be recovered using aggregate data). 
In order to judge the impact of aggregation on demand, it is convenient to use aggregation factors. ${ }^{9}$ Write aggregate demand as

$$
E_{t}\left(q_{i j t}\right)=b_{0 j}\left(p_{t}\right) E_{t}\left(m_{i t}\right)+b_{1 j}\left(p_{t}\right) \pi_{1 t} E\left(m_{i t}\right) \ln E\left(m_{i t}\right)+b_{2 j}\left(p_{t}\right) \pi_{2 t} E\left(m_{i t}\right) E\left(z_{i t}\right)
$$

where

$$
\pi_{1 t}=\frac{E\left(m_{i t} \ln m_{i t}\right)}{E\left(m_{i t}\right) \ln E\left(m_{i t}\right)} \text { and } \pi_{2 t}=\frac{E\left(m_{i t} z_{i t}\right)}{E\left(m_{i t}\right) E\left(z_{i t}\right)}
$$

The factors $\pi_{1 t}$ and $\pi_{2 t}$ show how the coefficients in (7) are adjusted if individual demand is evaluated at average income and average attributes, as in (8). $\pi_{1 t}$ reflects inequality in the income distribution through the entropy term $E\left(m_{i t} \ln m_{i t}\right)$ and $\pi_{2 t}$ reflects the distribution of income of the elderly, as the ratio of the elderly's share in aggregate income $E\left(m_{i t} z_{i t}\right) / E\left(m_{i t}\right)$ to the percentage of elderly $E\left(z_{i t}\right)$ in the population. Aggregation factors are useful for two reasons. First, if they are stable, then aggregate demand has similar structure to individual demand. Second, their average value indicates how much bias is introduced in estimation using aggregate data alone. ${ }^{10}$

In contrast, the distributional approach considers restrictions on the heterogeneity distribution $F_{t}\left(m_{i t}, z_{i t}\right)$. Suppose the density $d F_{t}\left(m_{i t}, z_{i t}\right)$ is assumed to be an explicit function of $E_{t}\left(m_{i t}\right), E\left(z_{i t}\right)$ and other parameters, such as variances and higher order moments. Then with a general nonlinear specification of individual demands $g_{i j t}$, we could solve (4) directly, expressing aggregate demand $E_{t}\left(q_{i j t}\right)$ as a function of those distributional parameters. Here, recovery of individual demand parameters from aggregate demand would be possible with sufficient variation in the distribution $F_{t}\left(m_{i t}, z_{i t}\right)$ over $t .{ }^{11}$

While conceptually different from exact aggregation, the distributional approach should not be thought of as a distinct alternative in empirical modeling. With distribution restrictions, formulating a model via direct integration in (4) may be difficult in practice. As such, distributional restrictions

\footnotetext{
${ }^{9}$ The use of aggregation factors was first proposed by Blundell, Pashardes and Weber (1993)

${ }^{10}$ For instance, in $(8), b_{1 j}\left(p_{t}\right)$ is the coefficient of $m_{i t} \ln m_{i t}$, whereas $b_{1 j}\left(p_{t}\right) \pi_{1 t}$ is the coefficient of $E\left(m_{i t}\right) \ln E\left(m_{i t}\right)$. If $\pi_{1 t}$ is stable, $\pi_{1 t}=\pi_{0}$, then $b_{1 j}\left(p_{t}\right) \pi_{1 t}$ is proportional to $b_{1 j}\left(p_{t}\right)$. In this sense, the structure of aggregate demand matches that of individual demand, but the use of aggregate data alone would estimate the individual coefficient with a proportional bias of $\pi_{0}$.

${ }^{11}$ Technically, what is necessary for recoverability is completeness of the class of income-attribute distributions; see Stoker (1984a).
} 
are often used together with exact aggregation restrictions, combining simplifying regularities of the income-attribute distribution with linearity restrictions in individual demands.

One example is with mean-scaling, as discussed in Lewbel (1990), where the distribution of income does not change relative shape but just scales up or down. Mean scaling can arise with a redistribution mechanism where individual budgets are all scaled the same, as in $m_{i t}=m_{i t-1}\left(E_{t}\left(m_{i t}\right) / E_{t-1}\left(m_{i t-1}\right)\right)$. This structure allows distributional statistics such as those in (7) to be computed from mean income only.

Another example arises from (distributional) exclusion restrictions. Certain attributes can be excluded from aggregate demand if their distribution conditional on income is stable over time; if

$$
d F_{t}\left(m_{i t}, z_{i t}\right)=f_{z}\left(z_{i t} \mid m_{i t}\right) d F_{t}^{*}\left(m_{i t}\right)
$$

where $f_{z}\left(z_{i t} \mid m_{i t}\right)$ does not vary with $t$, then from (4),

$$
E_{t}\left(q_{i j t}\right)=\int g_{j t}\left(p_{t}, m_{i t}, z_{i t}\right) f_{z}\left(z_{i t} \mid m_{i t}\right) d F_{t}^{*}\left(m_{i t}\right)=\int g_{j t}^{*}\left(p_{t}, m_{i t}\right) d F_{t}^{*}\left(m_{i t}\right)
$$

That is, $z_{i t}$ and its distributional statistics are excluded from the equation for aggregate demand. Aggregate demand reflects heterogeneity only through variation in the income distribution - there is not enough variation in the $z_{i t}$ distribution over $t$ to recover the individual effects from aggregate demand. We discuss various other examples of partial distribution restrictions below.

\subsubsection{Demand and Budget Share Models}

There has been a substantial amount of work on the precise structure of individual preferences and demands consistent with exact aggregation. The most well-known result of this kind is in the extreme case where the aggregate model simply relates average demands $E_{t}\left(q_{i j t}\right)$ to the vector of relative prices $p_{t}$ and average expenditure $E_{t}\left(m_{i t}\right)$. Gorman (1953) showed that this required preferences to be quasi-homothetic; with individual demands linear in $m_{i t}$.

Omitting reference to attributes $z_{i t}$ for now, the general formulation for exact aggregation has 
demands of the form.

$$
q_{i j t}=a_{0 j}\left(p_{t}\right)+b_{0 j}\left(p_{t}\right) h_{0}\left(m_{i t}\right)+\ldots+b_{M j}\left(p_{t}\right) h_{M}\left(m_{i t}\right)
$$

with aggregate demands given as

$$
E_{t}\left(q_{i j t}\right)=a_{0 j}\left(p_{t}\right)+b_{0 j}\left(p_{t}\right) E_{t}\left[h_{0}\left(m_{i t}\right)\right]+\ldots+b_{M j}\left(p_{t}\right) E_{t}\left[h_{M}\left(m_{i t}\right)\right]
$$

As above, provided there is sufficient variation in the statistics $E_{t}\left[h_{1}\left(m_{i t}\right)\right], \ldots, E_{t}\left[h_{M}\left(m_{i t}\right)\right]$, the coefficients $a_{0 j}\left(p_{t}\right), b_{0 j}\left(p_{t}\right), . ., b_{M j}\left(p_{t}\right)$, and hence individual demands, can be fully recovered from aggregate data.

Lau (1977, 1982) originally proposed the exact aggregation framework, and demonstrated that demands of the form (12) were not only sufficient but also necessary for exact aggregation, or aggregation without distributional restrictions (c.f. Stoker (1993) and Jorgenson, Lau and Stoker (1982)). Muellbauer (1975) studied a related problem, and established results for the special case of (12) with only two income terms. ${ }^{12}$ They both showed several implications of applying integrability restrictions to (12). If demands are zero at zero total expenditure, then $a_{0 j}\left(p_{t}\right)=0$. The budget constraint implies that one can set $h_{0}\left(m_{i t}\right)=m_{i t}$, without loss of generality. With homogeneity of degree zero in prices and incomes, one can assert the forms of the remaining income terms, which include the entropy form $h_{1}\left(m_{i t}\right)=m_{i t} \ln m_{i t}$ and the power form $h_{1}\left(m_{i t}\right)=m_{i t}^{\theta}$. This theory provides the background requirements for specific exact aggregation demand models, such as those we discuss below. ${ }^{13}$

The tradition in empirical demand analysis is to focus on relative allocations, and estimate equations for budget shares. The exact aggregation form (12) is applied to budget shares for this purpose. In particular, if we set $a_{0 j}\left(p_{t}\right)=0$ and $h_{0}\left(m_{i t}\right)=m_{i t}$ in (12), then budget shares $w_{i j t}=p_{j t} q_{i j t} / m_{i t}$ take on a similar linear form. We have

$$
w_{i j t}=\frac{p_{j t} q_{i j t}}{m_{i t}}=b_{0 j}\left(p_{t}\right)+b_{1 j}\left(p_{t}\right) h_{1}\left(m_{i t}\right)+\ldots+b_{M j}\left(p_{t}\right) h_{M}\left(m_{i t}\right)
$$

\footnotetext{
${ }^{12}$ Muellbauer (1975) studied the conditions under which aggregate budget shares would depend only on a single representative income value, which turned out to be analogous to the exact aggregation problem with only two expenditure terms.

${ }^{13}$ See also Lewbel $(1989 b, 1991,1993)$ and Stoker (1984a,1984b).
} 
where $b_{0 j}\left(p_{t}\right), \ldots, b_{M j}\left(p_{t}\right)$ and $h_{1}\left(m_{i t}\right), \ldots, h_{M}\left(m_{i t}\right)$ are redefined in the obvious way. If we denote individual expenditure weights as $\mu_{i t}=m_{i t} / E_{t}\left(m_{i t}\right)$, then aggregate budget shares are

$$
\begin{aligned}
\frac{E_{t}\left(p_{j t} q_{i j t}\right)}{E_{t}\left(m_{i t}\right)} & \equiv E_{t}\left(\mu_{i t} w_{i j t}\right) \\
& =b_{0 j}\left(p_{t}\right)+b_{1 j}\left(p_{t}\right) E_{t}\left(\mu_{i t} h_{1}\left(m_{i t}\right)\right)+\ldots+b_{M j}\left(p_{t}\right) E_{t}\left(\mu_{i t} h_{M}\left(m_{i t}\right)\right)
\end{aligned}
$$

The same remarks on recoverability apply here: the individual budget share coefficients $b_{1 j}\left(p_{t}\right), \ldots, b_{M j}\left(p_{t}\right)$ can be identified with aggregate data with sufficient variation in the distributional terms $E_{t}\left(\mu_{i t} h_{1}\left(m_{i t}\right)\right)$, $\ldots, E_{t}\left(\mu_{i t} h_{M}\left(m_{i t}\right)\right)$ over time. As above, aggregation factors can be used to gauge the difference between aggregate shares and individual shares. We have

$$
\begin{aligned}
\frac{E_{t}\left(p_{j t} q_{i j t}\right)}{E_{t}\left(m_{i t}\right)} & =E_{t}\left(\mu_{i t} w_{i j t}\right) \\
& =b_{0}\left(p_{t}\right)+b_{1}\left(p_{t}\right) \pi_{1 t} h_{1}\left(E_{t}\left(m_{i t}\right)\right)+. .+b_{M}\left(p_{t}\right) \pi_{M t} h_{M}\left(E_{t}\left(m_{i t}\right)\right)
\end{aligned}
$$

where by construction

$$
\pi_{k t}=\frac{E_{t}\left(\mu_{i t} h_{k}\left(m_{i t}\right)\right)}{h_{k}\left(E_{t}\left(m_{i t}\right)\right)}, k=1, \ldots, M
$$

are the aggregation factors. These factors give a compact representation of the distributional influences that cause the aggregate model, and the elasticities derived from it, to differ from the individual model.

The budget share form (14) accommodates exact aggregation through the separation of income and price terms in its additive form. As before, when integrability restrictions are applied to (14), the range of possible model specifications is strongly reduced. A particularly strong result is due to Gorman (1981), who showed that homogeneity and symmetry restrictions imply that the rank of the $J \times(M+1)$ matrix of coefficients $\left[b_{m j}\left(p_{t}\right)\right]$ can be no greater than 3. Lau (1977), Lewbel (1991) and others have characterized the full range of possible forms for the income functions. 


\subsubsection{Aggregation in Rank 2 and Rank 3 Models}

Early exact aggregation models were of rank 2 (for a given value of attributes $z_{i t}$ ). With budget share equations of the form ${ }^{14}$

$$
w_{i j t}=b_{0 j}\left(p_{t}\right)+b_{1 j}\left(p_{t}\right) h_{1}\left(m_{i t}\right)
$$

preferences can be specified that give rise to either the log-form $h_{1}\left(m_{i t}\right)=\ln m_{i t}$ and the power form $h_{1}\left(m_{i t}\right)=m_{i t}^{\theta}$. Typically the former is adopted and this produces Engel curves that are the same as those that underlie the Almost Ideal model and the Translog model (without attributes). ${ }^{15}$ In this case aggregate shares have the form

$$
\frac{E_{t}\left(p_{j t} q_{i j t}\right)}{E_{t}\left(m_{i t}\right)}=E_{t}\left(\mu_{i t} w_{i j t}\right)=b_{0 j}\left(p_{t}\right)+b_{1 j}\left(p_{t}\right) \pi_{1 t} \ln E_{t}\left(m_{i t}\right)
$$

where the relevant aggregation factor is the following entropy measure for the $m_{i t}$ distribution:

$$
\pi_{1 t}=\frac{E_{t}\left(\mu_{i t} \ln m_{i t}\right)}{\ln E_{t}\left(m_{i t}\right)}=\frac{E_{t}\left(m_{i t} \ln m_{i t}\right)}{E_{t}\left(m_{i t}\right) \ln E_{t}\left(m_{i t}\right)}
$$

where we have recalled that $\mu_{i t}=m_{i t} / E_{t}\left(m_{i t}\right)$. The deviation of $\pi_{1 t}$ from unity describes the degree of bias in recovering (individual) price and income elasticities from aggregate data alone.

Distribution restrictions can be used to facilitate computation of the aggregate statistics as well as studying the aggregation factors. For instance, suppose income is lognormally distributed, with $\ln m_{i t}$ distributed normally with mean $\mu_{m t}$ and variance $\sigma_{m t}^{2}$. The aggregation factor (20) can easily be seen to be

$$
\pi_{1 t}=1+\frac{1}{2\left(\mu_{m t} / \sigma_{m t}^{2}\right)+1} .
$$

To the extent that the $\log$ mean and variance are in stable proportion, $\pi_{1 t}$ will be stable. If the $\log$ mean is positive, then $\pi_{1 t}>1$, indicating positive bias from using $\ln E_{t}\left(m_{i t}\right)$.

Distribution restrictions can also facilitate the more modest goal of a stable relationship between aggregate budget shares and aggregate total expenditure. For instance, suppose that the total expen-

\footnotetext{
${ }^{14}$ This is Muellbauer's(1975) PIGL form.

${ }^{15}$ It is worthwhile to note that with the power form, estimation of $\theta$ with aggregate data would be complicated, because the aggregation statistics would depend in a complicated way on $\theta$.
} 
diture distribution obeys

$$
E_{t}\left(m_{i t} \ln m_{i t}\right)=c_{1} E_{t}\left(m_{i t}\right)+c_{2} E_{t}\left(m_{i t}\right) \ln E_{t}\left(m_{i t}\right)
$$

Then aggregate budget shares are

$$
\frac{E_{t}\left(p_{j t} q_{i j t}\right)}{E_{t}\left(m_{i t}\right)}=b_{0 j}\left(p_{t}\right)+b_{1 j}\left(p_{t}\right)\left(c_{1}+c_{2} \ln E_{t}\left(m_{i t}\right)\right)
$$

so that a relationship of the form

$$
\frac{E_{t}\left(p_{j t} q_{i j t}\right)}{E_{t}\left(m_{i t}\right)}=\widetilde{b}_{0 j}\left(p_{t}\right)+\widetilde{b}_{1 j}\left(p_{t}\right) \ln E_{t}\left(m_{i t}\right)
$$

would describe aggregate data well.

Here, integrability properties from individual demands can impart similar restrictions to the aggregate relationship. Lewbel (1991) shows that if individual shares

$$
w_{i j t}=b_{0 j}\left(p_{t}\right)+b_{1 j}\left(p_{t}\right) \ln m_{i t}
$$

satisfy symmetry, additivity and homogeneity properties, then so will

$$
w_{i j t}=b_{0 j}\left(p_{t}\right)+b_{1 j}\left(p_{t}\right)\left(\kappa+\ln m_{i t}\right) .
$$

The analogy of (23) and (26) makes clear that if $c_{2}=1$, then the aggregate model will satisfy symmetry, additivity and homogeneity. As such, some partial integrability restrictions may be applicable at the aggregate level. ${ }^{16}$

As we discuss in section 2.2 below, rank 2 models of the form (18) fail on empirical grounds. Evidence points to the need for more extensive income effects (for given demographic attributes $z_{i t}$ ), such as available from rank 3 exact aggregation specifications. In particular, rank 3 budget share systems that include terms in $\left(\ln m_{i t}\right)^{2}$ (as well as individual attributes) seem to do a good job of fitting the data, such as the QUAIDS system of Banks, Blundell and Lewbel (1997), described further

\footnotetext{
${ }^{16}$ It is tempting to consider the case of $c_{1}=0, c_{2}=1$, which would imply that the aggregation factor $\pi_{1 t}=1$ (and no aggregation bias). However, that case appears impossible, although we do not provide a proof. For instance, if $m_{i t}$ were lognormally distributed, $c_{1}=0, c_{2}=1$, would only occur if $\ln m_{i t}$ had zero variance.
} 
in section 2.2 below. In these cases, corresponding to the quadratic term $\left(\ln m_{i t}\right)^{2}$, there will be an additional aggregation factor to examine,

$$
\pi_{2 t}=\frac{E_{t}\left(\mu_{i t}\left(\ln m_{i t}\right)^{2}\right)}{\left(\ln E_{t}\left(m_{i t}\right)\right)^{2}}=\frac{E_{t}\left(m_{i t}\left(\ln m_{i t}\right)^{2}\right)}{E_{t}\left(m_{i t}\right)\left(\ln E_{t}\left(m_{i t}\right)\right)^{2}} .
$$

In analogy to (22), one can define partial distributional restrictions so that aggregate shares are well approximated as a quadratic function of $\ln E_{t}\left(m_{i t}\right)$.

\subsubsection{Heterogeneous Attributes}

As we noted in our earlier discussion, the empirical analysis of individual level data has uncovered substantial demographic effects on demand. Here we reintroduce attributes $z_{i t}$ into the equations, to capture individual heterogeneity not related to income. Since $z_{i t}$ varies across consumers, for exact aggregation, $z_{i t}$ must be incorporated in a similar fashion to total expenditure $m_{i t}$. The budget share form (14) is extended generally to

$$
w_{i j t}=b_{0 j}\left(p_{t}\right)+b_{1 j}\left(p_{t}\right) h_{1}\left(m_{i t}, z_{i t}\right)+\ldots+b_{M j}\left(p_{t}\right) h_{M}\left(m_{i t}, z_{i t}\right)
$$

Restrictions from integrability theory must apply for each value of the characteristics $z_{i t}$. For instance, Gorman's rank theory implies that the share model can be rewritten with two terms that depend on $m_{i t}$, but there is no immediate limit on the number of $h$ terms that depend only on characteristics $z_{i t}{ }^{17}$

Budget share models that incorporate consumer characteristics in this fashion were first introduced by Jorgenson, Lau and Stoker $(1980,1982)$. Aggregation factors arise for attribute terms, that necessarily involve interactions between income and attributes. The simplest factors arise for terms that depend only on characteristics, as in $h_{j}\left(m_{i t}, z_{i t}\right)=z_{i t}$, namely

$$
\pi_{t}^{z}=\frac{E_{t}\left(\mu_{i t} z_{i t}\right)}{E_{t}\left(z_{i t}\right)}=\frac{E_{t}\left(m_{i t} z_{i t}\right)}{E_{t}\left(m_{i t}\right) E_{t}\left(z_{i t}\right)}
$$

\footnotetext{
${ }^{17}$ A simple linear transformation will not in general be consistent with consumer optimization. Blundell, Browning and Crawford (2003) show that if budget shares have a form that is additive in functions of $\ln m_{i t}$ and demographics, then if (i) Slutsky symmetry holds and (ii) the effects of demographics on budget shares are unrestricted then they have to be linear in $\ln m_{i t}$.
} 
This can be seen as the ratio of the income weighted mean of $z_{i t}$ to the unweighted mean of $z_{i t}$. If $z_{i t}$ is an indicator; say $z_{i t}=1$ for households with children and $z_{i t}=0$ for households without children, then $\pi_{j t}^{z}$ is the percentage of expenditure accounted for by households with children, $E_{t}\left(m_{i t} z_{i t}\right) / E\left(m_{i t}\right)$, divided the percentage of households with children, $E_{t}\left(z_{i t}\right)$.

More complicated factors terms arise with expenditure-characteristic effects; for example, if $h_{j}\left(m_{i t}, z_{i t}\right)=$ $z_{i t} \ln m_{i t}$ then the relevant aggregation factor is

$$
\pi_{1 t}^{z}=\frac{E_{t}\left(\mu_{i t} z_{i t} \ln m_{i t}\right)}{E_{t}\left(z_{i t}\right) \ln E_{t}\left(m_{i t}\right)}=\frac{E_{t}\left(m_{i t} z_{i t} \ln m_{i t}\right)}{E_{t}\left(m_{i t}\right) E_{t}\left(z_{i t}\right) \ln E_{t}\left(m_{i t}\right)}
$$

As before, in analogy to (22), one can derive partial distributional restrictions so that aggregate shares are well approximated as a function of $E_{t}\left(m_{i t}\right)$ and $E_{t}\left(z_{i t}\right)$.

\subsection{Empirical Evidence and the Specification of Aggregate Demand Models}

\subsubsection{What do Individual Demands Look Like?}

Demand behavior at the individual household level is nonlinear. As we have mentioned, it is not realistic to assume that demands are linear in total expenditures and relative prices. To illustrate typical shapes of income structure of budget shares, Figures 1 and 2 present estimates of Engel curves of two commodity groups for the demographic group of married couples without children, in the British Family Expenditure Survey (FES). ${ }^{18}$ Each figure plots the fitted values of a polynomial (quadratic) regression in log total expenditure, together with a nonparametric kernel regression. We see that for food expenditures, an equation that expressed the food share as a linear function of log expenditure would be roughly correct. For alcohol expenditures, the income structure is more complex, requiring quadratic terms in log expenditure. Moreover, as one varies the demographic group, the shapes of the analogous Engel curves are similar, but they vary in level and slope.

The QUAIDS model of (Banks, Blundell and Lewbel (1997)) seems to be sufficiently flexible to

\footnotetext{
${ }^{18}$ The FES is a random sample of around 7,000 households per year. The commodity groups are non-durable expenditures grouped into: food-in, food-out, electricity, gas, adult clothing, children's clothing and footwear, household services, personal goods and services, leisure goods, entertainment, leisure services, fares, motoring and gasoline. More precise definitions and descriptive statistics are available on request.
} 
Figure 1: Nonparametric Engel Curve: Food Share

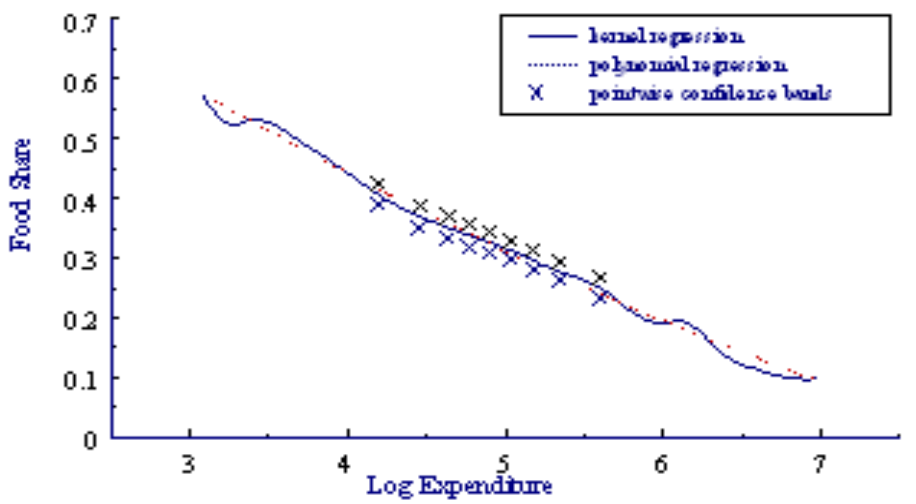

Figure 2: Nonparametric Engel curve: Alcohol Share

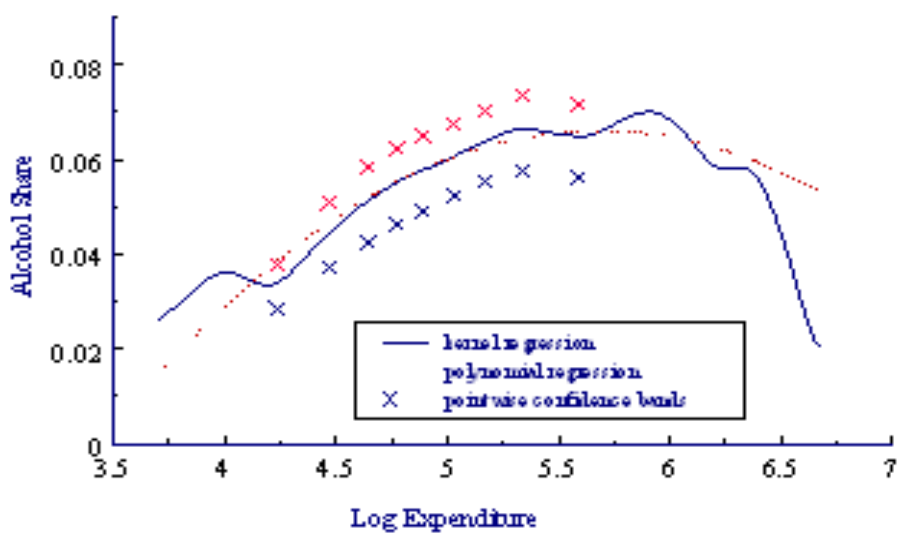


capture these empirical patterns. In the QUAIDS model, expenditure shares have the form

$$
w_{i j t}=\alpha_{j}+\gamma_{j}^{\prime} \ln p_{t}+\beta_{j}\left(\ln m_{i t}-\ln a\left(p_{t}\right)\right)+\lambda_{j} \frac{\left(\ln m_{i t}-\ln a\left(p_{t}\right)\right)^{2}}{c\left(p_{t}\right)}+u_{i j t}
$$

where $a\left(p_{t}\right)$ and $c\left(p_{t}\right)$ are given as

$$
\begin{aligned}
& \ln a\left(p_{t}\right)=\alpha^{\prime} \ln p_{t}+\frac{1}{2} \ln p_{t}^{\prime} \Gamma \ln p_{t}, \\
& \ln c\left(p_{t}\right)=\beta^{\prime} \ln p_{t},
\end{aligned}
$$

with $\alpha=\left(\alpha_{1}, \ldots, \alpha_{N}\right)^{\prime}, \beta=\left(\beta_{1}, \ldots, \beta_{N}\right)^{\prime}, \lambda=\left(\lambda_{1}, \ldots, \lambda_{N}\right)^{\prime}$ and

$$
\Gamma=\left(\begin{array}{c}
\gamma_{1}^{\prime} \\
\vdots \\
\gamma_{N}^{\prime}
\end{array}\right)
$$

This generalizes the (linear) Almost Ideal demand system by allowing nonzero $\lambda_{i}$ values, with the denominator $c\left(p_{t}\right)$ required to maintain the integrability restrictions. Banks, Blundell and Lewbel (1997) do extensive empirical analysis, and establish the importance of the quadratic log expenditure terms for many commodities. Interestingly, they find no evidence of the rejection of integrability restrictions associated with homogeneity or symmetry.

To include demographic attributes, an attractive specification is the 'shape invariant' specification of Blundell, Duncan and Pendakur (1998). Suppose that $g_{j}^{0}\left(\ln m_{i}\right)$ denotes a 'base' share equation, then a shape invariant model specifies budget shares as

$$
w_{i j t}=g_{j}^{0}\left(\ln m_{i}-\phi\left(z_{i t}^{\prime} \boldsymbol{\theta}\right)\right)+\mathbf{z}_{i t}^{\prime} \varphi_{j} .
$$

The shape invariant version of the QUAIDS model allows demographic variation in the $\alpha_{j}$ terms. In Banks, Blundell and Lewbel (1997), the $\alpha_{j}, \beta_{j}$ and $\lambda_{j}$ terms in (31) are allowed to vary with many attributes $z_{i t}{ }^{19}$ Family size, family composition, labor market status, occupation and education are all found to be important attributes for many commodities. ${ }^{20}$

\footnotetext{
${ }^{19}$ For instance, $\alpha_{j}+\delta_{j}^{\prime} z_{i t}$ is used in place of $\alpha_{j}$, and similar specifications for $\beta_{j}$ and $\lambda_{j}$ terms.

${ }^{20}$ Various methods can be used to estimate the QUAIDS model, with the iterated moment estimator of Blundell and Robin (2000) particularly straightforward. Banks, Blundell and Lewbel (1997) deal with endogeneity of total expenditures, using various instruments. Finally, we note that Jorgenson and Slesnick (2005), have recently combined a translog demand model (of rank 3) with an intertemporal allocation model, to model aggregate demand and labor supply in the United States.
} 


\subsubsection{The Implications for Aggregate Behavior}

The stability and interpretation of aggregate relationships can be assessed from examining the appropriate aggregation factors. We can compute the empirical counterparts to the factors by replacing expectations with sample averages. For instance, $\pi_{1 t}$ of $(20)$ is estimated as

$$
\widehat{\pi}_{1 t}=\frac{\sum_{i}\left(\widehat{\mu}_{i t} \ln m_{i t}\right) / n_{t}}{\ln \left(\sum_{i} m_{i t} / n_{t}\right)}
$$

and $\pi_{t}^{z}$ of $(29)$ is estimated as

$$
\hat{\pi}_{t}^{z}=\frac{\sum_{i} \widehat{\mu}_{i t} z_{i t} / n_{t}}{\sum_{i} z_{i t} / n_{t}}
$$

where we recall that the weights have the form $\widehat{\mu}_{i t}=m_{i t} /\left(\sum_{i} m_{i t} / n_{t}\right)$. Similarly, quadratic terms in $\ln m_{i t}$ will require the analysis of the empirical counterpart to the term (27). Interactions of the $\beta$ and $\tau$ terms with demographic attributes necessitates examination of the empirical counterparts of terms of the form (30). We can also study aggregation factors computed over different subgroups of the population, to see how aggregate demand would vary over those subgroups.

Figures 3 presents the estimated $\pi_{t}^{z}$ term for the impact of children on household demands. This shows a systematic rise in the share of non-durable expenditure and services attributable to families with children over the 1980s and 1990s. The aggregate bias associated with using observed percentage of households with children (as opposed to the income distribution across households with and without children) varies from $15 \%$ to $25 \%$. The path of $\pi_{t}^{z}$ also follows the UK business cycle and the path of aggregate expenditure with a downturns in 1981 and 1992.

Figure 4 presents the estimated $\pi_{1 t}$ and $\pi_{2 t}$ terms relating to the $\ln m_{i t}$ and $\left(\ln m_{i t}\right)^{2}$ expressions in the QUAIDS demand model. It is immediately clear that these also display systematic time series variation, but in comparison to $\pi_{t}^{z}$ above, they increase over the first period of our sample and fall towards the end. The bias in aggregation exhibited for the $\left(\ln m_{i t}\right)^{2}$ term is more than double that exhibited for the $\ln m_{i t}$ term.

Figure 5 presents the aggregations factor for $\ln m_{i t}$ term delineated by certain household types. The baseline $\ln m$ line ("all") is the same as that in Figure 4. The other two lines correspond to interactions for couples as a group and for couples with children. While the time pattern of aggregation factors is 


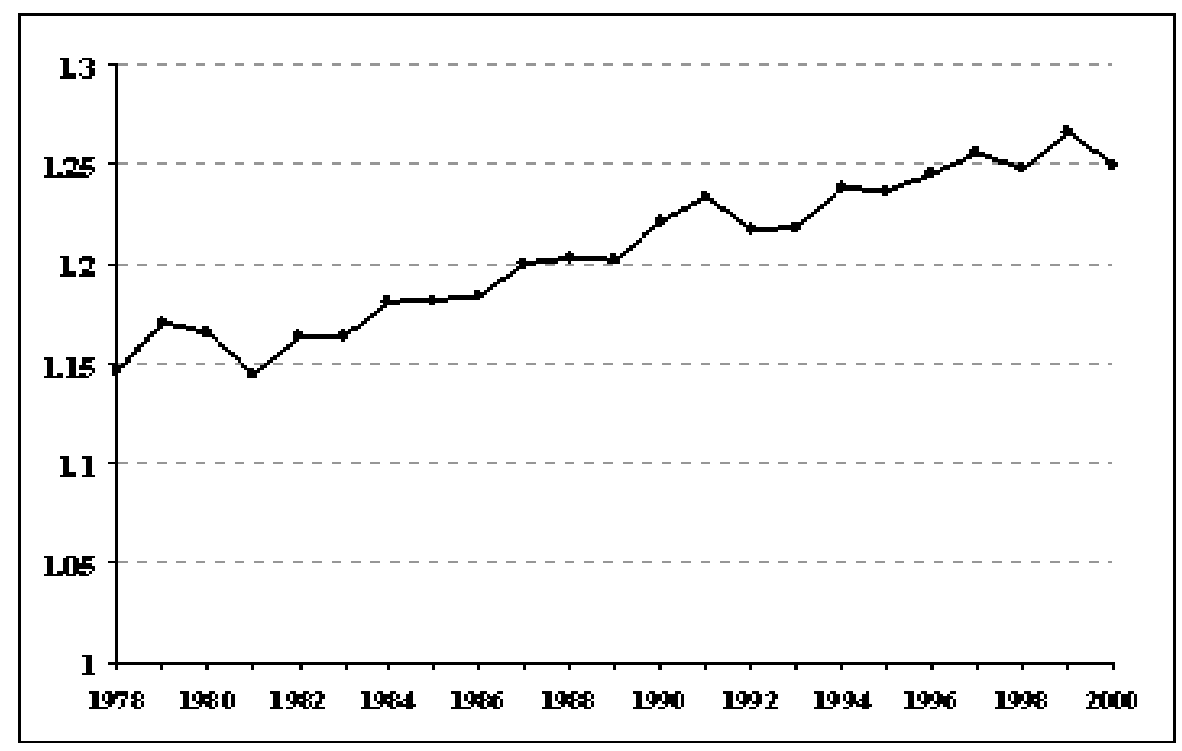

Figure 3: Aggregation Factor for Households With Children

similar, they are at different levels, indicating different levels of bias associated with aggregation over these subgroups.

Finally, it is worthwhile to mention some calculations we carried out on whether distributional restrictions such as (22) are capable of representing the aggregate movements in total expenditure data. Using the time series of distributional statistics from the FES data, we followed Lewbel (1991) and implemented each of these approximations as a regression. With demographic interaction terms, the aggregate model will only simplify if these conditions also apply to each demographic subgroup. In virtually every case, we found the fit of the appropriate regressions to be quite close (say $R^{2}$ in the range of .99). This gives support to the idea that aggregate demand relationships are reasonably stable empirically. However, the evidence on the $c_{j}$ terms implies that aggregation factors are substantially different than one, so again, estimates of the price and income elasticities using aggregate data alone will be not be accurate. 


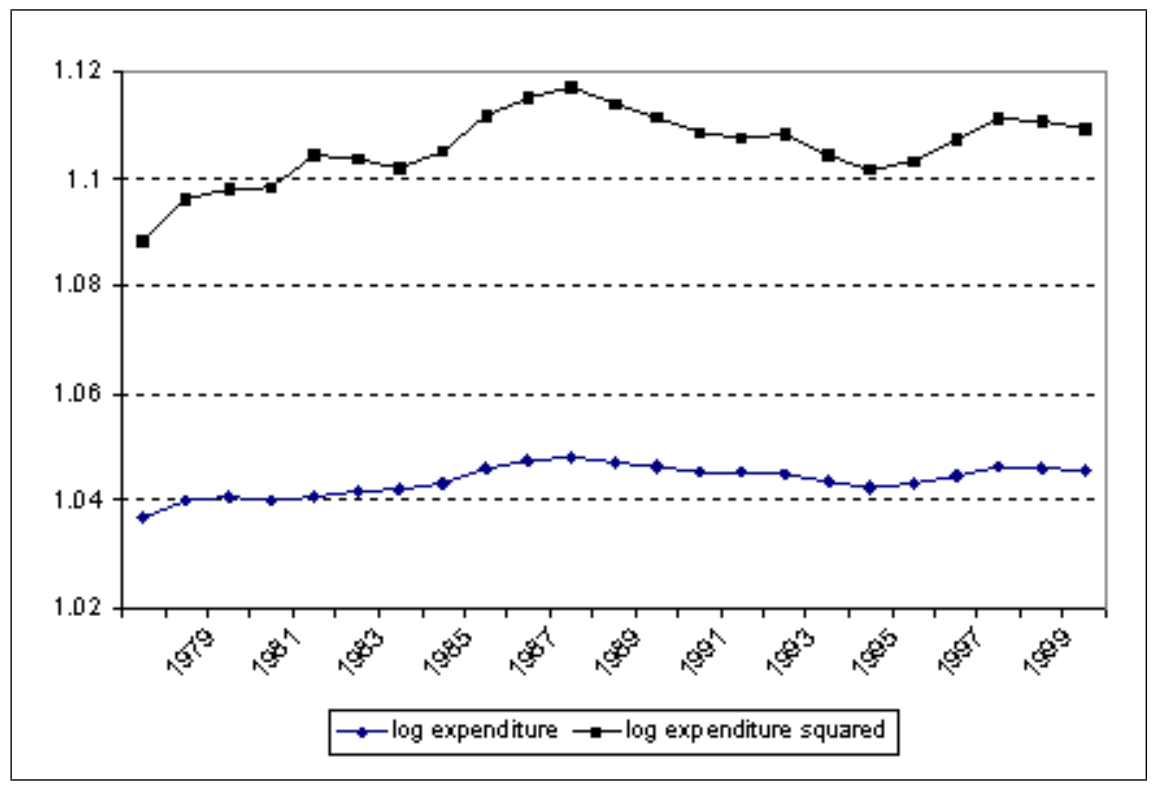

Figure 4: Aggregation Factors for Income Structure

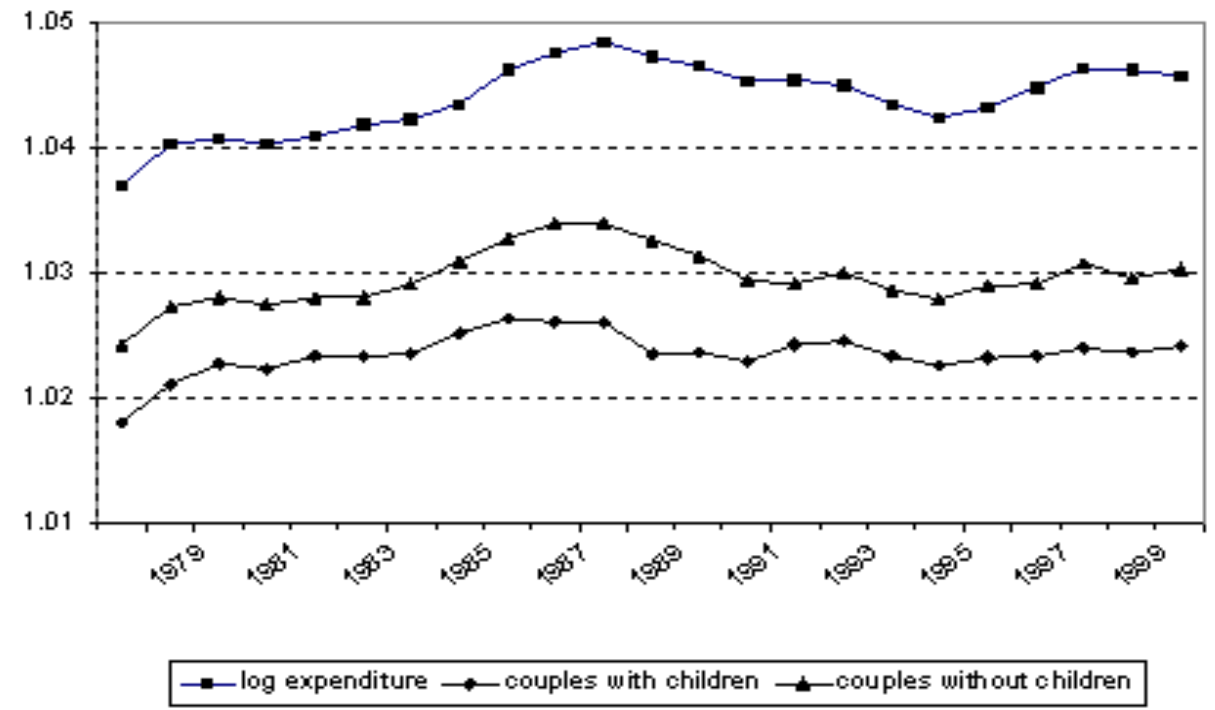

Figure 5: Aggregation Factors for Income Structure by Certain Household Types 


\subsection{Aggregation of Demand without Individual Structure}

We close with discussion of a nontraditional approach given in Hildenbrand (1994), which is to study specific aspects of aggregate demand structure without relying on assumptions on the behavior of individual consumers. This work makes heavy use of empirical regularities in the observed distribution of consumer expenditures across the population.

We can understand the nature of this approach from a simple example. Suppose we are interested in whether aggregate demand for good $j$ decreases when price $p_{j}$ increases (obeying the "Law of Demand"), and we omit reference to other goods and time $t$ for simplicity. Denote the conditional expectation of demand $q_{i j}$ for good $j$, given income $m_{i}$ and price $p_{j}$, as $g_{j}\left(p_{j}, m_{i}\right)$. Aggregate demand for good $j$ is

$$
E\left(q_{i j}\right)=G\left(p_{j}\right)=\int g\left(p_{j}, m\right) d F(m)
$$

and our interest in in whether $d G / d p_{j}<0$. Form this derivative, applying the Slutsky decomposition to $g\left(p_{j}, m\right)$ as

$$
\begin{aligned}
\frac{d G}{d p_{j}} & =\int\left[\left.\frac{d g}{d p_{j}}\right|_{c o m p}-g\left(p_{j}, m\right) \frac{d g}{d m}\right] d F(m) \\
& =\left.\int \frac{d g}{d p_{j}}\right|_{c o m p} d F(m)-\int g\left(p_{j}, m\right) \frac{d g}{d m} d F(m) \\
& =S \quad-A
\end{aligned}
$$

The price effect on aggregate demand decomposes into the mean compensated price effect $S$ and the mean income effect $A$. If we take $S$ as negative, which is fairly uncontroversial, then we know that $d G / d p_{j}<0$ if the income effect $A>0$. Looking once more at $A$ we can see various ways of ascertaining whether $A>0$ :

$$
A=\int g\left(p_{j}, m\right) \frac{d g}{d m} d F(m)=\frac{1}{2} \int \frac{d\left[g\left(p_{j}, m\right)^{2}\right]}{d m} d F(m)
$$

Without making any structural assumptions on $g\left(p_{j}, m\right)$, one could estimate $A$ with the first expression using nonparametric estimates of $g(\cdot)$ and its derivative. Or, we could examine directly whether the "spread" $g\left(p_{j}, m\right)^{2}$ is increasing with $m$, and if so, conclude that $A>0$. 
This gives the flavor of this work without doing justice to the details. The main contribution is to link up properties of aggregate demand directly with aspects of the distribution of demands across the population. Hildenbrand (1998) shows that increasing spread is a common phenomena in data on British households, and it is likely to be valid generally. More broadly, this work has stimulated extensive study of the distribution of household expenditures, with a different perspective than traditional demand modeling. Using nonparametric methods, Härdle, Hildenbrand and Jerison (1991) study aggregate income effects across a wide range of goods, and conclude that the 'law of demand' likely holds quite generally. Hildenbrand and Kneip (1993) obtain similar findings on income structure by directly examining the dimensionality of vectors of individual demands. ${ }^{21}$ See Hildenbrand (1994) for an overview of this work, as well as Hildenbrand (1998) for an examination of variations in the British expenditure distribution within a similar framework.

\section{Consumption and Wealth}

We now turn to a discussion of total consumption expenditures. Here the empirical problem is to characterize consumption expenditures over time periods, including how they relate to income and wealth. The individual level is typically that of a household (or an individual person, depending on data source). The economic aggregate to be modeled is average consumption expenditures over time, and we are interested in how aggregate consumption and saving relate to income and wealth across the economy, as well as interest rates. This relationship is essential for understanding how interest rates will evolve as the population changes demographically, for instance.

Consumption expenditures are determined through a forward looking plan, that takes into account the needs of individuals over time, as well as uncertainty in wealth levels. There is substantial evidence of demographic effects and nonlinearities in consumption at the individual level, ${ }^{22}$ so we will need to consider heterogeneity in tastes as before. Accordingly, aggregate consumption is affected by the structure of households and especially the age distribution, and aggregate consumption will be affected

\footnotetext{
${ }^{21}$ This is related to transformation modeling structure of Grandmont (1992). It is clear that the dimensionality of exact aggregation demand systems is given by the number of independent income/attribute terms, c.f. Diewert (1977) and Stoker (1984b).

${ }^{22}$ See Attanasio and Weber (1993) and Attanasio and Browning (1995), among many others.
} 
by inequality in the distribution of wealth. We are not concerned here with heterogeneity in market participation per se, as everyone has non-zero consumption expenditures. Later we discuss some issues raised by liquidity constraints, which have much in common with market participation modeling as described in Section 4 .

Our primary focus is on heterogeneity with regard to risks in income and wealth levels, and how the forward planning process is affected by them. We take into account the nature of the income and wealth shocks, as well as the nature of the credit markets that provide insurance against negative shocks.

We consider four different types of shocks, delineated by whether the effects are permanent or transitory, and whether they are aggregate, affecting all consumers, or individual in nature. Aggregate permanent shocks can refer to permanent changes in the productive capability of the economy - such as running out of a key natural resource, or skill-biased technical change - as well as to permanent changes in taxes or other policies that affect savings. Individual permanent shocks include permanent changes in an individual's ability to earn income, such as chronic bad health and long term changes in type and status of employment. Aggregate transitory shocks refer to temporary aggregate phenomena, such as exchange rate variation, bad weather, and so forth. Individual transitory shocks include to temporary job lay-offs, temporary illnesses, etc. Many different situations of uncertainty can be accounted for by combinations of these four different types of shocks.

In terms of risk exposure and markets, there are various scenarios to consider. With complete markets, all risks are insured, and an individual's consumption path is unaffected by the evolution of the individual's income over time. ${ }^{23}$ When markets are not complete, the extent of available insurance markets becomes important, and determines the degree to which different individual risks are important for aggregate consumption behavior. For example, in the absence of credit market constraints, idiosyncratic risks may be open to self-insurance. But in that case there may be little insurance available for aggregate shocks or even for permanent idiosyncratic shocks. Our discussion takes into account the type of income risks and how risk exposure affects aggregate consumption.

\footnotetext{
${ }^{23}$ See Atkeson and Ogaki (1996) for a model of aggregate expenditure allocation over time and to individual goods based on addilog preferences, assuming that complete markets exist.
} 
Most of our discussion focuses on individual consumption plans and their implications for aggregate consumption. Beyond this, we can consider the feedback effects on consumption and wealth generated through general equilibrium. For instance, if a certain group of consumers systematically save more than others, then in equilibrium those consumers will be wealthier, and their savings behavior will be a dominant influence on the evolution of aggregate wealth. The study of this important topic is in its infancy, and has been analyzed primarily with calibrated macroeconomic growth models. We include a discussion of some of this work.

\subsection{Consumption Growth and Income Shocks}

In our framework, in each period $t$, individual $i$ chooses consumption expenditures $c_{i t}$ by maximizing expected utility subject to an asset accumulation constraint. Individual $i$ has heterogeneous attributes $z_{i t}$ that affect preferences. There is a common, riskless interest rate $r_{t}$. We assume separability between consumption and labor supply in each time period, and separability of preferences over time.

We begin with a discussion of aggregation with quadratic preferences. This allows us to focus on

the issues of different types of income shocks and insurance, without dealing with nonlinearity. In Section 3.2, we consider more realistic preferences that allow precautionary saving.

When individual within-period utilities are quadratic in current consumption, we have the familiar certainty-equivalent formulation in which there is no precautionary saving. Within-period utilities are given as

$$
U_{i t}\left(c_{i t}\right)=-\frac{1}{2}\left(a_{i t}-c_{i t}\right)^{2}
$$

for $c_{i t}<a_{i t}$. We model individual heterogeneity by connecting $a_{i t}$ to individual attributes as

$$
a_{i t}=\alpha+\beta^{\prime} z_{i t}
$$

With the discount rate equal to the real interest rate, maximizing the expected sum of discounted utilities gives the following optimal plan for the consumer (Hall (1978)),

$$
\Delta c_{i t}=\Delta \alpha_{i t}+\xi_{i t}=\beta^{\prime} \Delta z_{i t}+\xi_{i t}
$$


Defining $\Omega_{i, t-1}$ as the information set for individual $i$ in period $t-1$, the consumption innovation $\xi_{i t}$ obeys

$$
E\left[\xi_{i t} \mid \Omega_{i, t-1}\right]=0
$$

In what follows we will use a time superscript to denote this conditional expectation, namely $E^{t-1}(\cdot) \equiv$ $E\left[\cdot \mid \Omega_{i, t-1}\right]$ to distinguish it from the population average in period $t$ (which uses a time subscript as in $\left.E_{t}(\cdot)\right)$. Notice, the model $(38)$ is linear in the change in attributes $\Delta z_{i t}$ with constant coefficients $\beta$, plus the consumption innovation. In other words, this model is in exact aggregation form with regard to the attributes $z_{i t}$ that affect preferences.

\subsubsection{Idiosyncratic Income Variation and Aggregate Shocks}

When the only uncertainty arises from real income, the consumption innovation $\xi_{i t}$ can be directly related to the stochastic process for income. We begin by spelling out the income process in a meaningful way. Express income $y_{i t}$ as the sum of transitory and permanent components

$$
y_{i t}=y_{i t}^{P}+y_{i t}^{T} \text {. }
$$

and assume that the transitory component is serially independent. We assume that the permanent component follows a random walk

$$
y_{i t}^{P}=y_{i t-1}^{P}+\eta_{i t}^{P}
$$

where the innovation $\eta_{i t}^{P}$ is serially independent.

Next, decompose these two components into a common aggregate effect and an idiosyncratic effect

$$
\begin{aligned}
& \eta_{i t}^{P}=\eta_{t}+\varepsilon_{i t}, \\
& y_{i t}^{T}=u_{t}+v_{i t} .
\end{aligned}
$$

Here $\eta_{t}$ is the common aggregate permanent shock, $\varepsilon_{i t}$ is the permanent shock at the individual level, $u_{t}$ is the aggregate transitory shock and $v_{i t}$ is the individual transitory shock - the four types of income shocks discussed above. This mixture of permanent and transitory shocks has been found to provide a good approximation to the panel data process for log incomes, see MaCurdy (1982) and Meghir and 
Pistaferri (2004). We assume that the individual shocks are normalized to average to zero across the population, namely $E_{t}\left(\varepsilon_{i t}\right)=0$ and $E_{t}\left(v_{i t}\right)=0$.

The stochastic process for individual income then takes the form

$$
\Delta y_{i t}=\eta_{t}+\varepsilon_{i t}+\Delta u_{t}+\Delta v_{i t}
$$

The stochastic process for aggregate income has the form

$$
\Delta E_{t}\left(y_{i t}\right)=\eta_{t}+\Delta u_{t}
$$

where, again, $E_{t}$ to denotes expectation (associated with averaging) across the population of agents at time $t$.

\subsubsection{Income Shocks and Insurance}

The first scenario is where individual (and aggregate) shocks are not insurable. Here the optimal consumption innovation $\xi_{i t}$ for the individual will adjust fully to permanent income shocks but only adjust to the annuity value of transitory shocks. To see this, again suppose that real interest rates are constant and equal the discount rate. Under quadratic preferences (36), consumption growth can be written (Deaton and Paxson (1994))

$$
\Delta c_{i t}=\beta^{\prime} \Delta z_{i t}+\eta_{t}+\varepsilon_{i t}+\tau_{t}\left(\Delta u_{t}+\Delta v_{i t}\right)
$$

where $\tau_{t}$ is the annuitization rate for a transitory shock with planning over a finite horizon. ${ }^{24}$ Clearly, expected growth is determined by preference attributes as

$$
E^{t-1}\left(\Delta c_{i t}\right)=E\left(\Delta c_{i t} \mid \Omega_{i, t-1}\right)=\beta \Delta z_{i t}
$$

Aggregate consumption has the form

$$
\Delta E_{t}\left(c_{i t}\right)=\beta^{\prime} \Delta E_{t}\left(z_{i t}\right)+\eta_{t}+\tau_{t} \Delta u_{t}
$$

\footnotetext{
${ }^{24}$ If $L$ is the time horizon, then $\tau_{t}=r /\left[(1+r)\left(1-(1+r)^{-(L-t+1)}\right)\right]$. Clearly $\tau_{t} \rightarrow 0$ as $r \rightarrow 0$. Note that for a small interest rate, we have $\tau_{t} \approx 0$, so that the transitory shocks become irrelevant for consumption growth.
} 
Thus, the aggregate data is described exactly by a representative agent model with quadratic preferences and characteristics $E_{t}\left(z_{i t}\right)$ facing a permanent/transitory income process. ${ }^{25}$

For the second scenario, suppose individual shocks can be fully insured, either through informal processes or through credit markets. Now individual consumption growth depends only on aggregate shocks

$$
\Delta c_{i t}=\beta^{\prime} \Delta z_{i t}+\eta_{t}+\tau_{t} \Delta u_{t}
$$

Consequently, with (48), we will have

$$
\Delta c_{i t}=\beta^{\prime}\left(\Delta z_{i t}-\Delta E_{t}\left(z_{i t}\right)\right)+\Delta E_{t}\left(c_{i t}\right) .
$$

Thus, consumption growth at the individual level equals aggregate consumption growth plus an adjustment for individual preferences.

Finally, the third scenario is where all shocks (aggregate and individual) are fully insurable. Now individual consumption growth will be the planned changes $\beta^{\prime} \Delta z_{i t}$ only, and aggregate consumption growth will be the mean of those changes $\beta^{\prime} \Delta E_{t}\left(z_{i t}\right)$. This is the most complete "representative agent" case, as complete insurance has removed the relevance of all income risks.

\subsubsection{Incomplete Information}

It is interesting to note that in our simplest framework, incomplete information can cause aggregate consumption to fail to have random walk structure. In particular, suppose individual shocks are not completely insurable and consumers cannot distinguish between individual and aggregate shocks. To keep it simple, also assume that there are no varying preference attributes $z_{i t}$. Following Pischke (1995), individual $i$ will view the income process (44) as an MA(1) process:

$$
\Delta y_{i t}=\zeta_{i t}-\theta \zeta_{i t-1},
$$

where the $\theta$ parameter is a function of the relative variances of the shocks.

\footnotetext{
${ }^{25}$ Aside from the drift term $\beta^{\prime} \Delta E_{t}\left(z_{i t}\right)$, aggregate consumption is a random walk. In particular, the orthogonality conditions $E^{t-1}\left(\eta_{t}+\tau_{t} \Delta u_{t}\right)=E\left(\eta_{t}+\tau_{t} \Delta u_{t} \mid \Omega_{i, t-1}\right)=0$ hold at the individual level and therefore also hold at the aggregate level.
} 
Changes in individual consumption are simply

$$
\Delta c_{i t}=(1-\theta) \zeta_{i t}
$$

Note that it is still the case that $E^{t-1}\left(\Delta c_{i t}\right)=E\left(\Delta c_{i t} \mid \Omega_{i, t-1}\right)=0$. However, from (51) we have that

$$
\Delta c_{i t}-\theta \Delta c_{i t-1}=(1-\theta) \Delta y_{i t}
$$

Replacing $\Delta y_{i t}$ by (44) and averaging over consumers we find

$$
\Delta E_{t}\left(c_{i t}\right)=\theta \Delta E_{t-1}\left(c_{i t-1}\right)+(1-\theta)\left(\eta_{t}+\Delta u_{t}\right)
$$

so that aggregate consumption is clearly not a random walk.

\subsection{Aggregate Consumption Growth with Precautionary Saving}

With quadratic preferences, consumption growth can be written as linear in individual attributes in exact aggregation form - and we were able to isolate the impacts of different kinds of income shocks and insurance scenarios. To allow for precautionary saving, we must also account for nonlinearity in the basic consumption process. For this, we now consider the most standard consumption model used in empirical work, that based on Constant Relative Risk Aversion (CRRA) preferences.

\subsubsection{Consumption Growth with CRRA Preferences}

We assume that within-period utility is

$$
U_{i t}\left(c_{i t}\right)=e^{a_{i t}}\left[\frac{c_{i t}^{1-\frac{1}{s_{i t}}}}{1-\frac{1}{s_{i t}}}\right]
$$

where $a_{i t}$ permits scaling in marginal utility levels (or individual subjective discount rates), and $s_{i t}$ is the intertemporal elasticity of substitution, reflecting the willingness of individual $i$ to trade off today's consumption for future consumption. As before, we will model the heterogeneity in $a_{i t}$ and $s_{i t}$ via individual attributes $z_{i t}$.

We now adopt a multiplicative stochastic income process, with the decomposition expressed in 
$\log$-form as

$$
\Delta \ln y_{i t}=\eta_{t}+\varepsilon_{i t}+\Delta u_{t}+\Delta v_{i t}
$$

The permanent and transitory error components in the income process are decomposed into aggregate and individual terms, as in (44). As noted before, this income growth specification is closely in accord with the typical panel data models of income or earnings, and it will neatly complement our equations for consumption growth with CRRA preferences. In addition, we assume that the interest rate $r_{t}$ is small, for simplicity, and is not subject to unanticipated shocks.

With precautionary savings, consumption growth depends on the conditional variances of the uninsurable components of shocks to income. Specifically, with CRRA preferences (54) and log income process (55), we have the following log-linear approximation for consumption growth ${ }^{26}$

$$
\Delta \ln c_{i t}=\rho r_{t}+\left(\beta+\varphi r_{t}\right)^{\prime} z_{i t}+k_{1} \sigma_{i t}^{t-1}+k_{2} \sigma_{A t}^{t-1}+\kappa_{1} \varepsilon_{i t}+\kappa_{2} \eta_{t}
$$

where $\sigma_{i t}^{t-1}$ is the conditional variance of idiosyncratic risk (conditional on $t-1$ information $\Omega_{i, t-1}$ ) and $\sigma_{A t}^{t-1}$ is the conditional variance of aggregate risk. The attributes $z_{i t}$ represent the impact of heterogeneity in $a_{i t}$, or individual subjective discount rates, and the intertemporal elasticity of substitution $s_{i t}=\rho+\beta+\varphi^{\prime} z_{i t}$. Typically in empirical applications, $z_{i t}$ will include levels and changes in observable attributes, and unobserved factors may also be appropriate. ${ }^{27}$ As before,

$$
\begin{aligned}
& E\left(\varepsilon_{i t} \mid \Omega_{i, t-1}\right)=E^{t-1}\left(\varepsilon_{i t}\right)=0 \\
& E\left(\eta_{t} \mid \Omega_{i, t-1}\right)=E^{t-1}\left(\eta_{t}\right)=0
\end{aligned}
$$

To sum up, in contrast to the quadratic preference case, the growth equation (56) is nonlinear in consumption, and it includes conditional variance terms which capture the importance of precautionary saving.

A consistent aggregate of the individual model (56) is given by

$$
E_{t}\left(\Delta \ln c_{i t}\right)=\rho r_{t}+\left(\beta+\varphi r_{t}\right)^{\prime} E_{t}\left(z_{i t}\right)+k_{1} E_{t}\left(\sigma_{i t}^{t-1}\right)+k_{2} \sigma_{A t}^{t-1}+\kappa_{2} \eta_{t}
$$

\footnotetext{
${ }^{26}$ See Blundell and Stoker (1999) for a precise derivation and discussion of this approximation.

${ }^{27}$ See Banks, Blundell and Brugiavini (2001) for a detailed empirical specification of consumption growth in this form.
} 
where $E_{t}\left(\Delta \ln c_{i t}\right)$ refers to the population mean of the cross-section distribution of $\Delta \ln c_{i t}$ in period $t$, and so on. The $t$ subscript again refers to averaging across the population of consumers, and we have normalized $E_{t}\left(\varepsilon_{i t}\right)=0$ as before. Provided $E_{t}\left(\ln c_{i t-1}\right)=E_{t-1}\left(\ln c_{i t-1}\right)$, equation (59) gives a model of changes over time in $E_{t}\left(\ln c_{i t}\right)$, which is a natural aggregate given the log form of the model (56).

However, $E_{t}\left(\ln c_{i t}\right)$ is not the aggregate typically observed nor is it of much policy interest. Of central interest is per-capita consumption $E_{t}\left(c_{i t}\right)$ or total consumption $n_{t} E_{t}\left(c_{i t}\right)$. Deriving an equation for the appropriate aggregates involves dealing with the 'log' nonlinearity, to which we now turn. ${ }^{28}$

\subsubsection{How is Consumption Distributed?}

Since the individual consumption growth equations are nonlinear, we must make distributional assumptions to be able to formulate an equation for aggregate consumption. In the following, we will assume lognormality of various elements of the consumption process. Here we point out that this is motivated by an important empirical regularity - namely, individual consumption does appear to be lognormally distributed, at least in developed countries such as the United States and the United Kingdom.

Figure 6 shows the distribution of log-consumption using US consumer expenditure data across the last two decades. Consumption is taken as real expenditure on non-durables and services, and is plotted by five year bands to achieve a reasonable sample size. Each log-consumption distribution has a striking resemblance to a normal density. In the experience of the authors, this result is often replicated in more disaggregated data by year and various demographic categorizations, such as birth cohort, and also in other countries including in the Family Expenditure Survey data for the UK. Given this regularity, one would certainly start with log-normality assumptions such as those we make below, and any subsequent refinements would need to preserve normality of the marginal distribution of log consumption.

\footnotetext{
${ }^{28}$ If we evaluate the individual model at aggregate values, we get

$$
\Delta \ln E_{t}\left(c_{i t}\right)=\rho r_{t}+\left(\beta+\varphi r_{t}\right) E_{t}\left(z_{i t}\right)+k_{2} \sigma_{A t}^{t-1}+\omega_{t} .
$$

Here $\omega_{t}$ is a 'catch-all' term containing the features that induce aggregation bias, that will not satisfy the orthogonality condition $E^{t-1}\left(\omega_{t}\right)=0$.It is also worthwhile to note that empirical models of aggregate consumption also typically omit the terms $E_{t}\left(z_{i t}\right)$ and $k_{2} \sigma_{A t}^{t-1}$.
} 

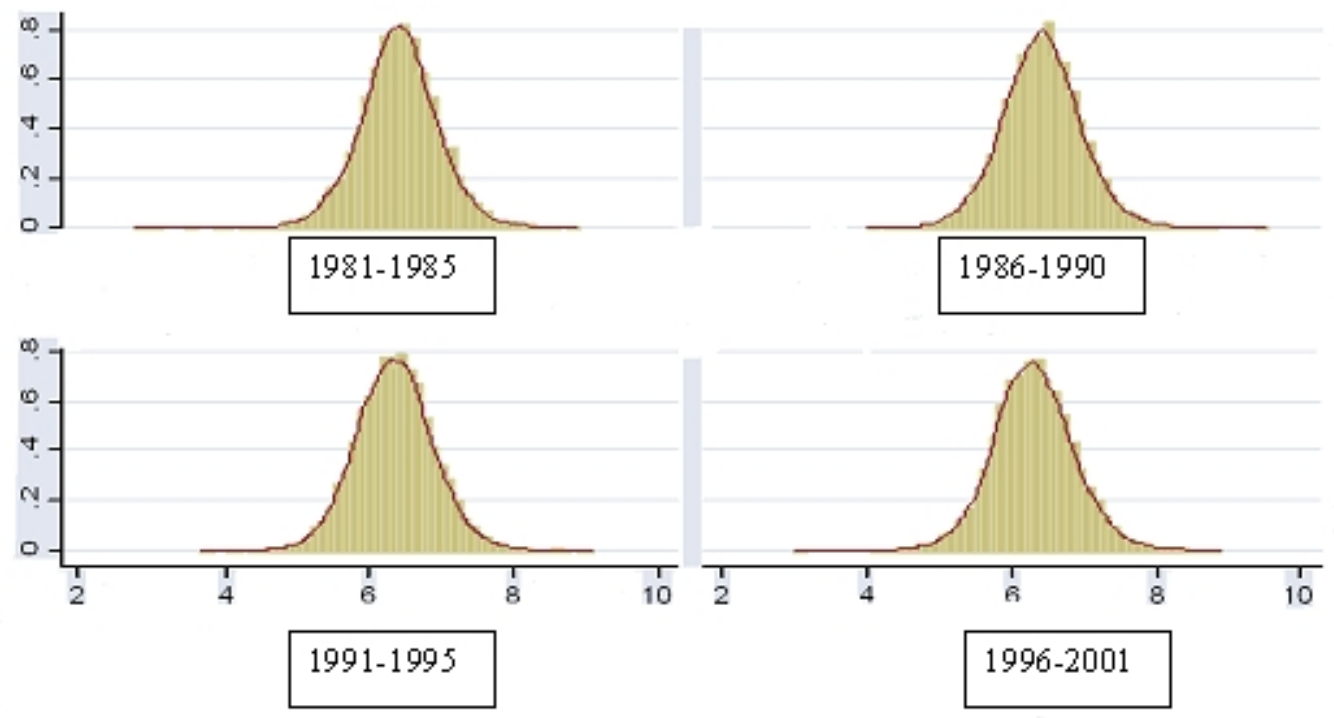

Figure 6: The Distribution of Log Nondurable Consumption Expenditure: US 1981-2001 


\subsubsection{Insurance and Aggregation with Precautionary Saving}

As with our previous discussion, we must consider aggregation under different scenarios of insurance for income risks. We again assume that agents have the same information set, namely $\Omega_{i, t-1}=\Omega_{t-1}$ for all $i, t$.

We begin with the scenario in which there is full insurance for individual risks, or pooling of idiosyncratic risk across individuals. Here insurance and credit markets are sufficiently complete to remove individual risk terms in individual income and consumption streams, so $\varepsilon_{i t}=0$ and $\sigma_{i t}^{t-1}=0$ for all $i, t$. The individual model (56) becomes

$$
\Delta \ln c_{i t}=\rho r_{t}+\left(\beta+\varphi r_{t}\right)^{\prime} z_{i t}+k_{2} \sigma_{A t}^{t-1}+\kappa_{2} \eta_{t}
$$

with $E^{t-1}\left(\eta_{t}\right)=0$. The mean-log model (59) is now written as

$$
E_{t}\left(\ln c_{i t}\right)-E_{t}\left(\ln c_{i t-1}\right)=\rho r_{t}+\left(\beta+\varphi r_{t}\right)^{\prime} E_{t}\left(z_{i t}\right)+k_{2} \sigma_{A t}^{t-1}+\kappa_{2} \eta_{t}
$$

The relevant aggregate is per-capita consumption $E_{t}\left(c_{i t}\right)$. Per-capita consumption is given by

$$
\begin{aligned}
E_{t}\left(c_{i t}\right) & =E_{t}\left[\exp \left(\ln c_{i t-1}+\rho r_{t}+\left(\beta+\varphi r_{t}\right)^{\prime} z_{i t}+k_{2} \sigma_{A t}^{t-1}+\kappa_{2} \eta_{t}\right)\right] \\
& =\exp \left(\rho r_{t}+k_{2} \sigma_{A t}^{t-1}+\kappa_{2} \eta_{t}\right) \cdot E_{t}\left[c_{i t-1} \exp \left(\left(\beta+\varphi r_{t}\right)^{\prime} z_{i t}\right)\right]
\end{aligned}
$$

with the impact of log-linearity arising in the final term, a weighted average of attribute terms interacted with lagged consumption $c_{i t-1}$.

Of primary interest is aggregate consumption growth, or the log-first difference in aggregate consumption

$$
\Delta \ln E_{t}\left(c_{i t}\right)=\ln \left(\frac{E_{t}\left(c_{i t}\right)}{E_{t-1}\left(c_{i t-1}\right)}\right)
$$

This is expressed as

$$
\begin{aligned}
\Delta \ln E_{t}\left(c_{i t}\right) & =\rho r_{t}+k_{2} \sigma_{A t}^{t-1}+\kappa_{2} \eta_{t} \\
+ & \ln \left(\frac{E_{t}\left[c_{i t-1} \exp \left(\left(\beta+\varphi r_{t}\right)^{\prime} z_{i t}\right)\right]}{E_{t}\left(c_{i t-1}\right)}\right)+\ln \left(\frac{E_{t}\left(c_{i t-1}\right)}{E_{t-1}\left(c_{i t-1}\right)}\right) .
\end{aligned}
$$


Aggregate consumption growth reflects the interest and risk terms that are common to all consumers, a weighted average of attribute terms, and the $\log$-difference in the average of $c_{i t-1}$ at time $t$ versus time $t-1$.

Notice first that even if $z_{i t}$ is normally distributed, we cannot conclude that $\ln c_{i t}$ is normal. We also need (as a sufficient condition) that $\ln c_{i t-1}$ is normal at time $t$ to make such a claim. This would further seem to require normality of $\ln c_{i t-2}$ at $t-1$, and so forth into the distant past. In any case, we cover this situation with the broad assumption:

The distribution of $c_{i t-1}$ is the same in period $t-1$ and $t$.

That is, the population could grow or shrink, but the distribution of $c_{i t-1}$ is unchanged. Under that assumption, we can drop the last term in (63)

$$
\ln \left(\frac{E_{t}\left(c_{i t-1}\right)}{E_{t-1}\left(c_{i t-1}\right)}\right)=0
$$

Lagging the individual model (60) gives an equation for $c_{i t-1}$, but there is no natural way to incorporate that structure directly into the equation for aggregate current consumption $E_{t}\left(c_{i t}\right) .{ }^{29}$ Therefore, we further assume

$$
\left(\begin{array}{l}
\ln c_{i t-1} \\
\theta_{t}^{\prime} z_{i t}
\end{array}\right) \sim \mathcal{N}\left(\left(\begin{array}{l}
\mu_{c_{-1} t} \\
\theta_{t}^{\prime} E_{t}\left(z_{i t}\right)
\end{array}\right),\left[\begin{array}{ll}
\sigma_{c-1, t}^{2} & \Sigma_{z c_{-1}, t}^{\prime} \theta_{t} \\
\theta_{t}^{\prime} \Sigma_{z c_{-1}, t} & \theta_{t}^{\prime} \Sigma_{z z, t} \theta_{t}
\end{array}\right]\right) .
$$

where we have set $\theta_{t}=\left(\beta+\varphi r_{t}\right)$. This assumption says that

$$
\begin{aligned}
& \ln c_{i t-1}+\theta_{t}^{\prime} z_{i t} \\
& \sim \mathcal{N}\left(\mu_{c_{-1} t}+\theta_{t}^{\prime} E_{t}\left(z_{i t}\right), \sigma_{c_{-1}, t}^{2}+\theta_{t}^{\prime} \Sigma_{z z, t} \theta_{t}+2 \theta_{t}^{\prime} \Sigma_{z c_{-1}, t}\right)
\end{aligned}
$$

and

$$
\ln c_{i t-1} \sim \mathcal{N}\left(\mu_{c_{-1} t}, \sigma_{c_{-1}, t}^{2}\right)
$$

\footnotetext{
${ }^{29}$ This is because of the potential dependence of $c_{i t-1}$ on the same factors as $c_{i t-2}$, and so forth.
} 
We can now solve for an explicit solution to (63): apply (65), (67) and (68) and rearrange to get

$$
\begin{aligned}
& \Delta \ln E_{t}\left(c_{i t}\right)=\rho r_{t}+\left(\beta+\varphi r_{t}\right)^{\prime} E_{t}\left(z_{i t}\right)+k_{2} \sigma_{A t}^{t-1}+\kappa_{2} \eta_{t} \\
&+\frac{1}{2}\left[\left(\beta+\varphi r_{t}\right)^{\prime} \Sigma_{z z, t}\left(\beta+\varphi r_{t}\right)+2\left(\beta+\varphi r_{t}\right) \Sigma_{z c_{-1}, t}\right]
\end{aligned}
$$

This is the aggregate model of interest, expressing growth in per-capita consumption as a function of the mean of $z$, the conditional variance terms from income risk, and the covariances between attributes $z$ and lagged consumption $c_{i t-1}$. Thus shows how individual heterogeneity manifests itself in aggregate consumption through distributional variance terms. These variance terms vary with $r_{t}$ if the intertemporal elasticity of substitution varies over the population.

Now consider the scenario where some individual risks are uninsurable. This reintroduces terms $\varepsilon_{i t}$ and $\sigma_{i t}^{t-1}$ in consumption growth at the individual model, and we must be concerned with how those permanent risks are distributed across the population. In particular, we assume in each period that each individual draws idiosyncratic risk from a common conditional distribution, so that $\sigma_{i t}^{t-1}=\sigma_{I t}^{t-1}$ for all $i$. The individual consumption growth equation (56) now appears as

$$
\Delta \ln c_{i t}=\rho r_{t}+\left(\beta+\varphi r_{t}\right)^{\prime} z_{i t}+k_{1} \sigma_{I t}^{t-1}+k_{2} \sigma_{A t}^{t-1}+\kappa_{1} \varepsilon_{i t}+\kappa_{2} \eta_{t}
$$

The mechanics for aggregation within this formulation are similar to the previous case, including the normalization $E_{t}\left(\varepsilon_{i t}\right)=0$, but we need deal explicitly with how the permanent individual shocks $\varepsilon_{i t}$ covary with $\ln c_{i t-1}$. As above, we adopt a stability assumption (64). We then extend (66) to assume that $\left(\ln c_{i t-1},\left(\beta+\varphi r_{t}\right)^{\prime} z_{i t}, \varepsilon_{i t}\right)$ is joint normally distributed. The growth in aggregate average consumption is now given by

$$
\Delta \ln E_{t}\left(c_{i t}\right)=\rho r_{t}+\left(\beta+\varphi r_{t}\right)^{\prime} E_{t}\left(z_{i t}\right)+k_{1} \sigma_{I t}^{t-1}+k_{2} \sigma_{A t}^{t-1}+\kappa_{2} \eta_{t}+\frac{1}{2}\left(\Lambda_{t}\right)
$$

where

$$
\begin{gathered}
\Lambda_{t}=\left(\beta+\varphi r_{t}\right)^{\prime} \Sigma_{z z, t}\left(\beta+\varphi r_{t}\right)+\kappa_{1}^{2} \sigma_{\varepsilon, t}^{2}+2\left(\beta+\varphi r_{t}\right)^{\prime} \Sigma_{z c_{-1}, t} \\
+2 \kappa_{1} \sigma_{\varepsilon c_{-1}, t}+2 \kappa_{1} \Sigma_{\varepsilon z, t}\left(\beta+\varphi r_{t}\right) .
\end{gathered}
$$

While complex, this formulation underlines the importance of the distribution of risk across the population. In contrast to the full information model (69), there is a term $\sigma_{\varepsilon, t}^{2}$ in.$\Lambda_{t}$ that reflects the 
changing variance in consumption growth. The term $\sigma_{I t}^{t-1}$ captures how idiosyncratic risk varies, based on $t-1$ information.

We have not explicitly considered unanticipated shocks to the interest rate $r_{t}$, or heterogeneity in rates across individuals. ${ }^{30}$ Unanticipated shocks in interest would manifest as a correlation between $r_{t}$ and aggregate income shocks, and would need treatment via instruments in estimation. Heterogeneity in rates could, in principle, be accommodated as with heterogeneous attributes. This would be especially complicated if the overall distributional structure were to shift as interest rates increased or decreased.

\subsection{Empirical Evidence on Aggregating the Consumption Growth Relationship}

There are two related aspects of empirical research that are relevant for our analysis of aggregation in consumption growth models. The first concerns the evidence on full insurance of individual risks. How good an approximation would such an assumption be? To settle this we need to examine whether there is evidence of risk pooling across different individuals and different groups in the economy. For example, does an unexpected change in pension rights, specific to one cohort or generation, get smoothed by transfers across generations? Are idiosyncratic health risks to income fully insured? Even though we may be able to cite individual cases where this perfect insurance paradigm clearly fails, is it nonetheless a reasonable approximation when studying the time series of aggregate consumption?

The second aspect of empirical evidence concerns the factors in the aggregate model (71) that are typically omitted in studies of aggregate consumption. From the point of view of estimating the intertemporal elasticity parameter $\rho$, how important are these aggregation factors? How well do they correlate with typically chosen instruments and how likely are they to contaminate tests of excess sensitivity performed with aggregate data?

\subsubsection{Evidence on Full Insurance and Risk Pooling Across Consumers}

If the full insurance paradigm is a good approximation to reality, then aggregation is considerably simplified and aggregate relationships satisfying the standard optimality conditions can be derived

\footnotetext{
${ }^{30}$ Zeldes (1989b) points out how differing marginal tax rates can cause interest $r_{t}$ to vary across consumers.
} 
with various conditions on individual preferences. There is a reasonably large and expanding empirical literature on the validity of the full insurance scenario, as well as complete markets scenario. This work is well reviewed in Attanasio (1998) and Browning, Hansen and Heckman (1998). Here we present evidence directly related to our discussion of consumption growth above. Two rather effective ways of analyzing failures of the full insurance paradigm fit neatly with our discussion.

One approach to evaluating the full insurance hypothesis is to look directly for evidence that unexpected shocks in income across different groups in the economy leads to differences in consumption patterns (as consistent with (56), which assumes no insurance). This is not a trivial empirical exercise. First, such income shocks have to be identified and measured. Second, there has to be a convincing argument that they would not be correlated with unobservable variables entering marginal utility, or observables such as labor supply (in a nonseparable framework).

Building on the earlier work by Cochrane (1991), Mace (1991), Hayashi, Altonji and Kotlikoff (1992) and Townsend (1994), the study by Attanasio and Davis (1996) presents rigorous and convincing evidence against the full insurance hypothesis using this approach. Low frequency changes in wages across different education and date-of-birth cohorts are shown to be correlated positively with systematic differences in consumption growth. More recently, Blundell, Pistaferri and Preston (2003) use a combination of the Panel Survey of Income Dynamics (PSID) and the Consumers Expenditure Survey (CES) to investigate insurance of permanent and transitory income shocks at the individual level. They find almost complete insurance to transitory shocks except among lower income households. They find some insurance to permanent shocks particularly among the younger and higher educated. But they strongly reject the complete insurance model.

The second approach to evaluating full insurance is to assume risk averse preferences and to model the evolution of idiosyncratic risk terms. In terms of the model (56), this approach examines the relevance of individual risk terms (e.g. $\sigma_{i t}^{t-1}$ ) once aggregate risk $\left(\sigma_{A t}^{t-1}\right)$ has been allowed for. This is addressed by looking across groups where the conditional variance of wealth shocks is likely to differ over time and to see whether this is reflected in differences in consumption growth. Following earlier work by Dynan (1993), Blundell and Stoker (1999), Caballero (1990), and Skinner (1988), the study by Banks, Blundell and Brugiavini (2001) presents evidence that differential variances of income shocks 
across date-of-birth cohorts do induce important differences in consumption growth paths.

\subsubsection{Aggregation Factors and Consumption Growth}

There are two issues: First, if one estimates a model with aggregate data alone, is there likely to be bias in the estimated parameters of interest? Second, will the omission of aggregation bias terms result in spurious inference concerning the presence of excess sensitivity of consumption to transitory income shocks.

With regard to bias, we consider the elasticity of intertemporal substitution $\rho$, which is normally a focus of studies of aggregate consumption. In Figure 7 we plot the aggregation factor

$$
\Delta \ln E_{t}\left(c_{i t}\right)-\Delta E_{t}\left(\ln c_{i t}\right)
$$

for the sample of married couples from the British FES, used to construct the aggregation factors for demand of section 2. The figure shows a systematic procyclical variation. We found the correlation coefficient between the real interest series and this factor to be significant. This indicates that there will exist an important aggregation bias in the estimated intertemporal substitution parameter from aggregate consumption data (with a log-linear growth model). This is confirmed in the study by Attanasio and Weber (1993), where aggregate data was constructed from micro survey information. ${ }^{31}$ They find an elasticity estimate for aggregate data of around .35, and the corresponding micro-level estimates were twice this size.

The study of excess sensitivity involves the use of lagged information as instrumental variables in the estimation of the consumption growth relationship. Omitting aggregation bias terms can invalidate the instruments typically used. For the consumption data used above, we computed the correlation of the aggregation factor with two typically used instrumental variables in consumption growth equations - lagged real interest rates and lagged aggregate consumption. The estimated correlation coefficient between these series and the omitted bias term was found to be strongly significant. ${ }^{32}$

\footnotetext{
${ }^{31}$ Attanasio and Weber (1993) also note a strong impact of omitting the cross-section variance of consumption growth.

${ }^{32}$ Detailed regression results available on request.
} 


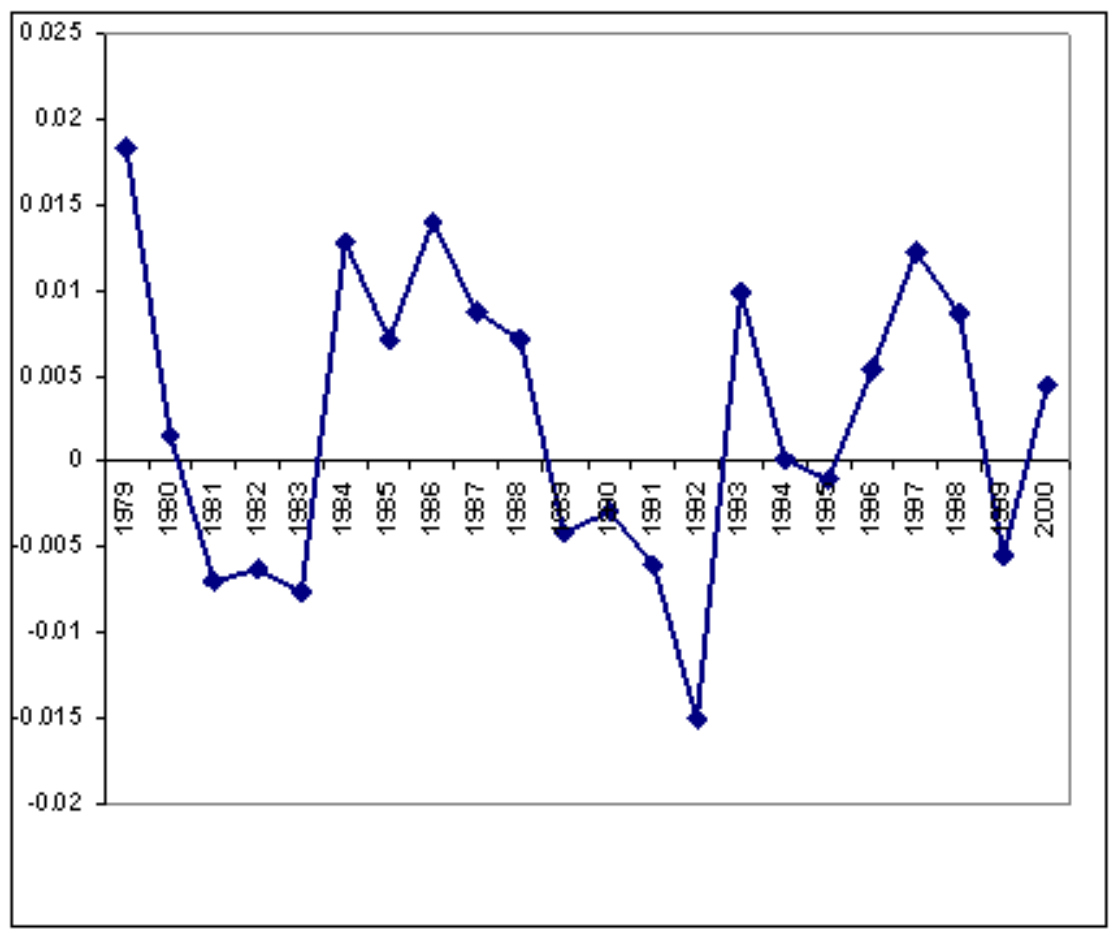

Figure 7: Aggregation Factor for Consumption Growth 
Together these results suggest that aggregation problems are likely to lead to serious bias in estimated intertemporal substitution parameters and also to exaggerate the presence of excess sensitivity in consumption growth regressions on aggregate data. Attanasio and Browning (1995) investigate this excess sensitivity issue in more detail and find that excess sensitivity still exists at the micro-data level but disappears once controls for age, labour supply variables and demographics are introduced in a flexible way. Moreover, these variables explain why excess sensitivity appears to vary systematically over the cycle.

It is an important finding that evidence of excess sensitivity vanishes once we move to individual data and include observable variables that are likely to impact preferences for the allocation of consumption over time. It has important consequences for our understanding of liquidity constraints and for partial insurance. It has implications for understanding the path of consumption growth over the cycle. It also has implications for the retirement-savings puzzle, or how consumption drops much more at retirement than is predicted by standard consumption growth equations. Banks, Blundell and Tanner (1998) find that once demographics and labor supply variables are allowed to affect the marginal utility of consumption, nearly two thirds of the retirement-savings puzzle disappears.

\subsection{Consumption and Liquidity Constraints}

Our previous discussion has focused on heterogeneity in wealth and income risk as it impinges on consumption. We now turn to a discussion of liquidity constraints on consumption, which generate a different kind of aggregation structure. The evidence for liquidity constraints is relatively limited. Most studies of consumption smoothing at the individual level find it difficult to reject the standard model once adequate care is taken in allowing for demographic and labor market interactions; see Attanasio and Weber (1995) and Blundell, Browning and Meghir (1994), for example. Much of the excess sensitivity found in aggregate studies can be attributed to aggregation bias as documented in Attanasio and Weber (1993), Goodfriend(1992) and Pischke (1995). However, there is some evidence that does point to the possibility that a fraction of consumers could be liquidity constrained at particular points in the life-cycle and business cycle. At the micro level some evidence can be found in the studies by Hayashi (1987), Zeldes (1989a), Jappelli (1990), Japelli and Pagano (1994), Meghir and Weber 
(1996) and Alessie, Devereaux and Weber (1997). As mentioned earlier, the Blundell, Pistaferri and Preston (2003) study shows that the consumption of low income households in the PSID does react to transitory shocks to income, which suggests that such households do not have access to credit markets to smooth such shocks.

For aggregation, liquidity constraints introduce regime structure into the population. Namely, liquidity constrained consumers constitute one regime, unconstrained consumers constitute another regime, and aggregate consumption will depend upon the relative distribution across regimes. This structure is particularly relevant for the reaction of consumption growth to increases in current income, since constrained consumers will show a stronger reaction than unconstrained consumers. In this section we discuss these basic issues, and indicate how a model of aggregates can be constructed. Blundell and Stoker (2003) works out the details for aggregate consumption models of this type.

There is some subtlety in considering what population groups are likely to be liquidity constrained. Poor households with a reasonably stable but low expected stream of income, may have little reason to borrow. More likely to be constrained are young consumers, who have much human capital but little financial wealth - college students or perhaps poor parents of able children. Such individuals may want to borrow against their future earned incomes but cannot, in part because their eventual income is higher than others, and the growth of their income with experience is higher. Clearly such consumers will react more than others to shocks in current income and wealth.

We start with the basic consumption model discussed earlier, with permanent and transitory shocks to income. As in (55), the change in current income for consumer $i$ at time $t$ is

$$
\Delta \ln y_{i t}=\eta_{t}+\varepsilon_{i t}+\Delta u_{t}+\Delta v_{i t}
$$

where $\eta_{t}+\varepsilon_{i t}$ is the permanent component and $\Delta u_{t}+\Delta v_{i t}$ is the transitory component. To keep things simple, we assume that permanent income shocks are not insurable, with log consumption given as

$$
\Delta \ln c_{i t}=\rho r_{t}+\left(\beta+\varphi r_{t}\right)^{\prime} z_{i t}+\eta_{t}+\varepsilon_{i t}
$$

where we assume the precautionary risk terms $\left(\sigma_{i t}^{t-1}, \sigma_{A t}^{t-1}\right)$ are included with the $z_{i t}$ effects. Note that (74) gives the consumption growth plan $\left(\rho r_{t}+\left(\beta+\varphi r_{t}\right)^{\prime} z_{i t}\right)$ as well as how consumption reacts 
to permanent shocks in income (here $\left.\eta_{t}+\varepsilon_{i t}\right)$.

Liquidity constraints affect the ability of consumers to finance their desired consumption growth path. We follow an approach similar to Zeldes (1989a), where the incidence of liquidity constraints depends on the degree of consumption growth the consumer is trying to finance and the existing stock of assets. In particular, liquidity constraints enter the growth plan only if they are binding in planning period $t-1$, and then the best response will always be to increase consumption growth so as to "jump" back up to the optimal path. If this response is further frustrated by a binding constraint in period $t$, consumption will simply grow by the amount of resources available.

This response structure is captured by additional terms in the equation (74). Let $I_{i t}$ denote the indicator

$$
I_{i t}=1[\text { consumer } i \text { is constrained in period } t-1]
$$

and suppose that a consumer who is constrained in period $t-1$ needs to increase consumption growth by $m_{i t}$ to return to the optimal growth plan. ${ }^{33}$ Then, consumption growth for unconstrained consumers is

$$
\Delta \ln c_{i t}=\rho r_{t}+\left(\beta+\varphi r_{t}\right)^{\prime} z_{i t}+I_{i t-1} m_{i t}+\eta_{t}+\varepsilon_{i t}
$$

We now model the constraints, as well as consumption growth for constrained consumers. With growth in income of $\Delta \ln y_{i t}$, consumer $i$ needs to finance a growth rate of

$$
\rho r_{t}+\left(\beta+\varphi r_{t}\right)^{\prime} z_{i t}+I_{i t-1} m_{i t}+\eta_{t}+\varepsilon_{i t}-\Delta \ln y_{i t}=\rho r_{t}+\left(\beta+\varphi r_{t}\right)^{\prime} z_{i t}+I_{i t-1} m_{i t}-\Delta u_{t}-\Delta v_{i t}
$$

for consumption at time $t$ to be on the growth plan. To model liquidity constraints at time $t$, suppose that consumer $i$ faces a borrowing constraint that is associated with a maximum rate of increase of consumption of

$$
\gamma+\delta A_{i t}+\zeta_{i t}
$$

\footnotetext{
${ }^{33}$ Various approaches have been applied to account for the jump term $m_{i t}$ in studies of micro level data. See Zeldes (1989a), Jappelli, Pischke and Souleles (1998), Garcia, Lasardi and Ng (1997), Alessie, Melenberg and Weber (1988), Alessie, Devereux and Weber (1997) and Attanasio and Weber (1998).
} 
where $A_{i t}$ is (say) accumulated financial wealth. Consumer $i$ is liquidity constrained in period $t$, or cannot maintain the consumption growth plan, if

$$
\rho r_{t}+\left(\beta+\varphi r_{t}\right)^{\prime} z_{i t}+I_{i t-1} m_{i t}-\Delta u_{t}-\Delta v_{i t}>\gamma+\delta A_{i t}+\zeta_{i t}
$$

which we indicate by $I_{i t}=1$, as above. In this case we assume that consumption growth is as large as possible, namely

$$
\Delta \ln c_{i t}=\Delta \ln y_{i t}+\gamma+\delta A_{i t}+\zeta_{i t}
$$

In terms of permanent and transitory terms of income growth, (78) may be rewritten

$$
\Delta \ln c_{i t}=\eta_{t}+\varepsilon_{i t}+\Delta u_{t}+\Delta v_{i t}+\gamma+\delta A_{i t}+\zeta_{i t}
$$

This is consumption growth for constrained consumers. The constraints have an impact; as consumption growth clearly depends on transitory income shocks and wealth levels.

Aggregate consumption growth will clearly depend on the proportion of consumers who are constrained and the proportion that are not. Consumers who were constrained last period will have a boost in their consumption growth to return to the optimal path. This regime switching structure is nonlinear in character. Therefore, to model aggregate consumption growth, we would need to specify distributional structure for all the elements that are heterogeneous across the population. We then aggregate over the population of unconstrained individuals with consumption growth (76) and the population of constrained individuals with consumption growth (79). Using log-normality assumptions, we carry out this development in Blundell and Stoker (2003). It is clear how aggregate consumption is affected by transitory income shocks, as well as the distribution of wealth.

\subsection{Equilibrium Effects}

As we mentioned at the start, one use of aggregate consumption equations is to study and understand the evolution of aggregate consumption and saving by themselves. Another important use is in studying equilibrium price and interest rate paths over time. This is an exercise in general equi-

librium analysis, and every feature that we have discussed above is relevant - consumer heterogeneity, heterogeneity in income and wealth risks, liquidity constraints, and the distribution of wealth. Fur- 
ther complicating this effort is the dynamic feedback that occurs wherein the level and distribution of wealth evolves as a result of the level and distribution of savings. These difficulties make it very hard to obtain analytical results on equilibrium. Nevertheless, it is extremely important to understand the nature of equilibrium here, including implications on prices and interest rates. We now discuss some recent progress that has been made using calibrated stochastic growth models. A leading example of this effort is provided by Krusell and Smith (1998), although the approach dates from at least Aiyagari (1994) and Heaton and Lucas (1996).

The Krusell-Smith setup has the following features. Consumers are infinitely-lived, with identical (within-period) CRRA preferences, but they are heterogeneous with regard to discount rates. Each consumer has a probability of being unemployed each period, providing transitory, idiosyncratic income shocks. Production arises from a constant returns-to-scale technology in labor and capital, and productivity shocks provide transitory aggregate shocks. Consumers can insure by investing in capital only, so that insurance markets are incomplete, and consumers' capital holdings cannot be negative (liquidity constraint). This setup is rich but in many ways is very simple. Nevertheless, in principle, in order to predict future prices, each consumer must keep track of the evolution of the entire distribution of wealth holdings.

Krusell and Smith's simulations show a rather remarkable simplification to this forecasting problem. For computing equilibrium and for consumer planning, it is only necessary for consumers to keep track of two things, the mean of the wealth distribution and the aggregate productivity shock. Thus there is an informational economy afforded in a similar fashion to a formal aggregation result; once mean wealth is known, the information contained in the distribution of wealth does not appear to improve forecasting very much. This is true even with heterogeneity of many types, including individual and aggregate income shocks (albeit transitory).

The reason for this is clear once the nature of equilibrium is examined. Most consumers, especially those with lowest discount rates, save enough to insure their risk to the point where their propensity to save out of wealth is essentially constant and unaffected by current income or output. Those consumers also account for a large fraction of the wealth. Therefore, saving is essentially a linear function in wealth, and only the mean of wealth matters to how much aggregate saving is done each period. The 
same is not true of aggregate consumption. There are many low wealth consumers who become unemployed and encounter liquidity constraints. Their consumption is much more sensitive to current output than that of wealthier consumers. In essence what is happening here is that the dynamics of the savings process concentrates wealth in the hands of a group that behaves in a homogeneous way, with a constant marginal propensity to save. This (endogenous) simplification allows planning to occur on the basis of mean wealth only.

It is certainly not clear how applicable this finding is beyond the context of this study. This is a computational finding that depends heavily on the specifics of this particular set-up. ${ }^{34}$ Nonetheless, this form of feedback has some appeal as a explanation of the smooth evolution of wealth distribution, as well as why forecasting equations (that fit well) are so often much simpler than one would expect from the process that underlies the data. The rich are different (and in this model, the difference makes them rich), but what is important for forecasting is how similar the rich are to one another. With equal saving propensities, it does not matter which group of rich people hold the most wealth.

In any case, the study of equilibrium effects is in its infancy, and it will certainly generate many valuable insights.

\section{Wages and Labor Participation}

Our final topic area is the analysis of wages and labor participation. Here the empirical problem is to understand the determinants of wages separately from the determinants of participation. The individual level is that of an individual worker. The economic aggregates to be modeled are aggregate wages and the aggregate participation rate, or one minus the unemployment rate. These statistics are central indicators for macroeconomic policy and for the measurement of economic well-being.

Our analysis is based on a familiar paradigm from labor supply. Potential wages are determined through human capital, and labor participation is determined by comparing potential wages to a reservation wage level. Empirically, there is substantial heterogeneity in the determinants of wages, and substantial heterogeneity in the factors determining labor participation, and both processes are

\footnotetext{
${ }^{34}$ Carroll (2000) makes a similar argument, with emphasis on the role of precautionary savings.
} 
nonlinear. In particular, it is typical to specify wage equations for individuals in log-form, and there is much evidence of age and cohort effects in wages and employment. As with demand and consumption, we will need to be concerned with heterogeneity in individual attributes. To keep things as simple as possible, we do not consider forward looking aspects of employment choice, and so are not concerned with heterogeneity in income and wealth risks.

Our primary focus is on heterogeneity in market participation. Aggregate wages depend on the rate of participation, and the important issues involve separation of the wage process from the participation decision. To put it very simply, suppose aggregate wages are increasing through time. Is this because typical wages for workers are increasing? Or, is it because low wage individuals are becoming unemployed? Do the sources of aggregate wage growth vary other the business cycle? The aggregation problem must be addressed to answer these questions.

We now turn to our basic model of wages that permits us to highlight these effects. We then show the size of these effects for aggregate wages in the UK, a country where there has been large and systematic changes in the composition of the workforce and in hours of work. A more extensive version of this model and the application is given in Blundell, Reed and Stoker (2003). They also summarize derivations of all aggregate equations given below.

\subsection{Individual Wages and Participation}

We begin with a model of individual wages in the style of Roy (1951), where wages are based on human capital or skill levels, and any two workers with the same human capital level are paid the same wage. Our framework is consistent with the proportionality hypothesis of Heckman and Sedlacek (1990), where there is no comparative advantage, no sectoral differences in wages for workers with the same human capital level, ${ }^{35}$ and the return to human capital is not a function of human capital endowments.

We assume that each worker $i$ possesses a human capital (skill) level of $H_{i}$. Suppose human capital is nondifferentiated, in that it commands a single price $r_{t}$ in each time period $t$. The wage paid to

\footnotetext{
${ }^{35}$ Heckman and Sedlacek (1985) provide an important generalization of this framework to multiple sector. See also Heckman and Honore (1990).
} 
worker $i$ at time $t$ is

$$
w_{t i}=r_{t} H_{i}
$$

Human capital $H_{i}$ is distributed across the population with mean

$$
E_{t}\left(\ln H_{i}\right)=\delta_{j s}
$$

where $\delta_{j s}$ is a level that varies with cohort $j$ to which $i$ belongs and education level $s$ of worker $i$. In other words, the log wage equation has the additive form

$$
\ln w_{i t}=\ln r_{t}+\delta_{j s}+\varepsilon_{i t}
$$

where $\varepsilon_{i t}$ has mean $0 .{ }^{36}$ We will connect $\delta_{j s}$ to observable attributes below.

To model participation, we assume that reservation wages $w_{i t}^{*}$ are lognormal

$$
\ln w_{i t}^{*}=\alpha \ln B_{i t}+\eta_{j s}+\zeta_{i t}
$$

where $\zeta_{i t}$ has mean 0 and where $B_{i t}$ is an exogenous income (welfare benefit) level that varies with individual characteristics and time. Participation occurs if $w_{i t} \geq w_{i t}^{*}$, or with

$$
\ln r_{t}-\alpha \ln B_{i t}+\delta_{j s}-\eta_{j s}+\varepsilon_{i t}-\zeta_{i t} \geq 0
$$

We represent the participation decision by the indicator $I_{i t}=1\left[w_{i t} \geq w_{i t}^{*}\right]$.

For aggregation over hours of work, it is useful to make one of two assumptions. One is to assume that the distribution of hours is fixed over time. The other is to assume that desired hours $h_{i t}$ are chosen by utility maximization, where reservation wages are defined as $h_{i t}\left(w^{*}\right)=h_{0}$ and $h_{0}$ is the minimum number of hours available for full-time work. We assume $h_{i t}(w)$ is normal for each $w$, and

\footnotetext{
${ }^{36}$ Clearly, there is an indeterminacy in the scaling of $r_{t}$ and $H_{t}$. Therefore, to study $r_{t}$, we will normalize $r_{t}$ for some year $t=0$ (say to $r_{0}=1$ ). We could equivalently set one of the $\delta$ 's to zero.
} 
approximate desired hours by

$$
\begin{aligned}
h_{i t} & =h_{0}+\gamma\left(\ln w_{i t}-\ln w_{i t}^{*}\right) \\
& =h_{0}+\gamma\left(\ln r_{t}-\alpha \ln B_{i t}+\delta_{j s}-\eta_{j s}+\varepsilon_{i t}-\zeta_{i t}\right)
\end{aligned}
$$

This is our base level specification. It is simple to extend this model to allow differentiated human capital, or differential cohort effects due to different labor market experience, which permits a wide range of education/cohort/time effects to be included (c.f. Blundell, Reed and Stoker (2003)). Because our examples involve log-linear equations and participation (or selection), we summarize the basic framework as

$$
\begin{aligned}
& \ln w_{i t}=\beta_{0}+\beta^{\prime} x_{i t}+\varepsilon_{i t}, \\
& I_{i t}=1\left[\alpha_{0}+\alpha^{\prime} z_{i t}+\nu_{i t}>0\right], \\
& h_{i t}=h_{0}+\gamma \cdot\left(\alpha_{0}+\alpha^{\prime} z_{i t}+\nu_{i t}\right)
\end{aligned}
$$

Here, $x_{i t}$ denotes education, demographic (cohort, etc.) and time effects, $z_{i t}$ includes out-of-work benefit variables, and $I_{i t}=1$ denotes participation. It is clear that the scale of $\gamma$ is not identified separately from the participation index $\alpha_{0}+\alpha^{\prime} z_{i t}+\nu_{i t}$, however we retain $\gamma$ to distinguish between the fixed hours case $\gamma=0$ and the variable hours case $\gamma \neq 0$.

Our notation distinguishes two types of individual heterogeneity in (85). The variables $x_{i t}$ and $z_{i t}$ are observable at the individual level, while $\varepsilon_{i t}$ and $\nu_{i t}$ are unobservable. Analysis of data on wages and participation at the individual level requires assumptions on the distribution of those unobservable elements, a process familiar from the literature on labor supply and selection bias. We now review some standard selection formulae here for later comparison with the aggregate formulations. Start with the assumption that the unobserved elements are normally distributed

$$
\left(\begin{array}{c}
\varepsilon_{i t} \\
\nu_{i t}
\end{array}\right) \sim \mathcal{N}\left(\left(\begin{array}{c}
0 \\
0
\end{array}\right),\left(\begin{array}{ll}
\sigma_{\varepsilon}^{2} & \sigma_{\varepsilon \nu} \\
\sigma_{\varepsilon \nu} & \sigma_{\nu}^{2}
\end{array}\right)\right)
$$

This allows us to apply some well known selection formulae (given in virtually every textbook of econometrics). The micro participation regression, or the proportion of participants given $x_{i t}$ and $z_{i t}$, 
is a probit model;

$$
E_{t}\left[I \mid x_{i t}, z_{i t}\right]=\Phi\left[\frac{\alpha_{0}+\alpha^{\prime} z_{i t}}{\sigma_{\nu}^{2}}\right] .
$$

The micro log-wage regression for participants is

$$
E_{t}\left[\ln w_{i t} \mid I_{i t}=1, x_{i t}, z_{i t}\right]=\beta_{0}+\beta^{\prime} x_{i t}+\frac{\sigma_{\varepsilon \nu}}{\sigma_{\nu}} \lambda\left[\frac{\alpha_{0}+\alpha^{\prime} z_{i t}}{\sigma_{\nu}^{2}}\right] .
$$

reflecting the typical (Heckman style) selection term, which adjusts the log-wage equation to the group of participating workers. ${ }^{37}$

\subsection{Aggregate Wages and Employment}

The aggregate of interest is average hourly earnings, where aggregation occurs over all workers, namely

$$
\bar{w}_{t}=\frac{\sum_{i \in(I=1)} h_{i t} w_{i t}}{\sum_{i \in(I=1)} h_{i t}}=\sum_{i \in(I=1)} \mu_{i t} w_{i t}
$$

where $i \in(I=1)$ denotes a participant (worker), $h_{i t} w_{i t}$ is the earnings of individual $i$ in period $t$, and $\mu_{i t}$ are the hours-weights

$$
\mu_{i t}=\frac{h_{i t}}{\sum_{i \in(I=1)} h_{i t}}
$$

Modelling the aggregate wage (89) requires dealing with log - nonlinearity of the basic wage equation, dealing with participation and dealing with the hours-weighting. All of these features require that distributional assumptions be made for (observable) individual heterogeneity. In particular, we make the following normality assumption for $x_{i t}$ and $z_{i t}$ :

$$
\left(\begin{array}{c}
\beta_{0}+\beta^{\prime} x_{i t} \\
\alpha_{0}+\alpha^{\prime} z_{i t}
\end{array}\right) \sim \mathcal{N}\left(\left(\begin{array}{c}
\beta_{0}+\beta^{\prime} E\left(x_{i t}\right) \\
\alpha_{0}+\alpha^{\prime} E\left(z_{i t}\right)
\end{array}\right),\left(\begin{array}{cc}
\beta^{\prime} \Sigma_{x x} \beta & \alpha^{\prime} \Sigma_{x z}^{\prime} \beta \\
\beta^{\prime} \Sigma_{x z} \alpha & \alpha^{\prime} \Sigma_{z z} \alpha
\end{array}\right)\right)
$$

or that the indices determining log-wage and employment are joint normally distributed. ${ }^{38}$

\footnotetext{
${ }^{37}$ Here $\Phi(\cdot)$ is the normal cumulative distribution function, and $\lambda(\cdot)=\phi(\cdot) / \Phi(\cdot)$, where $\phi(\cdot)$ is the normal density function.

${ }^{38}$ Assuming that the linear indices are normal is much weaker than assuming that $x_{i t}$ and $z_{i t}$ are themselves joint
} 
We now discuss some aggregate analogues of the micro regression equations, and then our final equation for the aggregate wage. The aggregate participation (employment) rate is

$$
E_{t}[I]=\Phi\left[\frac{\alpha_{0}+\alpha^{\prime} E\left(z_{i t}\right)}{\sqrt{\alpha^{\prime} \Sigma_{z z} \alpha+\sigma_{\nu}^{2}}}\right]
$$

using a formula originally due to McFadden and Reid (1975). Aggregate participation has the same form as the micro participation regression (87) with $z_{i t}$ replaced by $E\left(z_{i t}\right)$ and the spread parameter $\sigma_{\nu}$ replaced by the larger value $\sqrt{\alpha^{\prime} \Sigma_{z z} \alpha+\sigma_{\nu}^{2}}$, reflecting the influence of heterogeneity in the individual attributes that affect the participation decision. The mean of log-wages for participating (employed)

workers is

$$
E_{t}\left[\ln w_{i t} \mid I_{i t}=1\right]=\beta_{0}+\beta^{\prime} E\left(x_{i t} \mid I=1\right)+\frac{\sigma_{\varepsilon \nu}}{\sqrt{\alpha^{\prime} \Sigma_{z z} \alpha+\sigma_{\nu}^{2}}} \lambda\left[\frac{\alpha_{0}+\alpha^{\prime} E\left(z_{i t}\right)}{\sqrt{\alpha^{\prime} \Sigma_{z z} \alpha+\sigma_{\nu}^{2}}}\right],
$$

using a formula originally derived by McCurdy (1987). This matches the micro log-wage regression (88) with $x_{i t}$ replaced by $E\left(x_{i t} \mid I=1\right), z_{i t}$ replaced by $E\left(z_{i t}\right)$ and the spread parameter changed from $\sigma_{\nu}$ to $\sqrt{\alpha^{\prime} \Sigma_{z z} \alpha+\sigma_{\nu}^{2}}$. This is an interesting result, but doesn't deliver an equation for the aggregate wage $\bar{w}_{t}$.

Blundell, Reed and Stoker (2003) derive such an equation. The aggregate wage is given as

$$
\ln \bar{w}_{t}=\ln \frac{E\left[h_{i t} w_{i t} \mid I_{i t}=1\right]}{E\left[h_{i t} \mid I_{i t}=1\right]}=\beta_{0}+\beta^{\prime} E\left(x_{i t}\right)+\left[\Omega_{t}+\Psi_{t}+\Lambda_{t}\right]
$$

where the aggregation bias is comprised of a spread term

$$
\Omega_{t}=\frac{1}{2}\left[\beta^{\prime} \Sigma_{x x} \beta+\sigma_{\varepsilon}^{2}\right]
$$

plus two terms $\Psi_{t}$ and $\Lambda_{t}$, which represent separate sources of bias but have very complicated expressions. $^{39}$

multivariate normal. Such a strong structure would eliminate many important regressors, such as qualitative variables.

${ }^{39}$ In particular, we have

$$
\Psi_{t}=\ln \left\{\Phi\left[\frac{\alpha_{0}+\alpha^{\prime} E\left(z_{i t}\right)+\left(\beta^{\prime} \Sigma_{x z} \alpha+\sigma_{\varepsilon \nu}\right)}{\sqrt{\alpha^{\prime} \Sigma_{z z} \alpha+\sigma_{\nu}^{2}}}\right] / \Phi\left[\frac{\alpha_{0}+\alpha^{\prime} E\left(z_{i t}\right)}{\sqrt{\alpha^{\prime} \Sigma_{z z} \alpha+\sigma_{\nu}^{2}}}\right]\right\},
$$


What these terms represent can be seen most easily by the following construction. Begin with the individual wage equation evaluated at mean attributes, $\beta_{0}+\beta^{\prime} E\left(x_{i t}\right)=E_{t}\left(\ln w_{i t}\right)$, or overall mean log wage. Adding $\Omega_{t}$ adjusts for log-nonlinearity, as

$$
\ln E_{t}\left(w_{i t}\right)=E_{t}\left(\ln w_{i t}\right)+\Omega_{t}
$$

Adding $\Psi_{t}$ adjusts for participation, as

$$
\ln E\left[w_{i t} \mid I_{i t}=1\right]=\ln E_{t}\left(w_{i t}\right)+\Psi_{t}
$$

Finally, adding $\Lambda_{t}$ adjusts for hours-weighting, as

$$
\begin{aligned}
\ln \bar{w}_{t} & =\ln E\left[w_{i t} \mid I_{i t}=1\right]+\Lambda_{t} \\
& =E_{t}\left(\ln w_{i t}\right)+\Omega_{t}+\Psi_{t}+\Lambda_{t}
\end{aligned}
$$

Thus, the bias expressions are complicated but the roles of $\Omega_{t}, \Psi_{t}$ and $\Lambda_{t}$ are clear. In words, the term $\Omega_{t}$ captures the variance of returns, observable and unobservable. The term $\Psi_{t}$ reflects composition changes within the selected sample of workers from which measured wages are recorded. The term $\Lambda_{t}$ reflects changes in the composition of hours and depends on the size of the covariance between wages and hours.

The formulation (93) of the log aggregate wage $\ln \bar{w}_{t}$ thus captures four important sources of variation. First, aggregate wages increase if the distribution of log wages shifts to the right, which is a the typical "well-being" interpretation of aggregate wage movements. ${ }^{40}$ This source is reflected by the

$$
\Lambda_{t} \equiv \ln \left[\frac{h_{0}+\gamma \alpha_{0}+\gamma \alpha^{\prime} E\left(z_{i t}\right)+\gamma \beta^{\prime} \Sigma_{x z} \alpha+\gamma \sigma_{\varepsilon \nu}+\gamma \sqrt{\alpha^{\prime} \Sigma_{z z} \alpha+\sigma_{\nu}^{2}} \cdot \lambda_{\sigma_{e v}, t}^{a}}{h_{0}+\gamma \alpha_{0}+\gamma \alpha^{\prime} E\left(z_{i t}\right)+\gamma \sqrt{\alpha^{\prime} \Sigma_{z z} \alpha+\sigma_{\nu}^{2}} \cdot \lambda_{t}^{a}}\right]
$$

\footnotetext{
${ }^{40}$ Comparing $\ln \bar{w}_{i t}$ to mean log wage $E\left(\ln w_{i t}\right)$ is in line with the tradition of measuring "returns" from coefficients in $\log$ wage equations estimated with individual data; c.f. Solon, Barsky and Parker (1994). Other comparisons are possible, and some may be preferable on economic grounds. For instance, if aggregate production in the economy has total human capital $\left(\sum_{i} H_{i}\right)$ as an input, then the appropriate price for that input is $r_{t}$, so one might want to compare $\ln \bar{w}_{t}$ to $\ln r_{t}$ for a more effective interpretation. In any case, it is useful to point out that if $E\left(\ln H_{i}\right)$ is constant over time, then comparing $\ln r_{t}$ to $\ln \bar{w}_{t}$ is the same as comparing $E_{t}\left(\ln w_{i t}\right)$ to $\ln \bar{w}_{t}$.
} 
mean $\beta_{0}+\beta^{\prime} E\left(x_{i t}\right)$ of $\log$ wages. Second, because individual wages are given in log form, aggregate wages will increase with increased spread of the log wage distribution, as reflected by the heterogeneity term $\Omega_{t}$. Third, aggregate wages will increase if the benefit threshold increases, causing more lower wage individuals to decide not to participate. This is reflected in the participation term $\Psi_{t}$. Fourth, aggregate wages will increase if the hours of higher wage individuals increase relative to lower wage individuals, which is captured by the hours adjustment term $\Lambda_{t}$. The aggregate model (93) permits estimation of these separate effects.

This framework could be relaxed in many ways. We can allow all variance terms to be time varying, as well as many of the basic behavioral parameters. If the normality assumption on the overall log wage and participation index is not accurate for the whole population, the population can be segmented, with separate aggregate equations developed for each segment. These variations, among others, are discussed in Blundell, Reed and Stoker (2003).

\subsection{Empirical Analysis of British Wages}

The different sources of aggregate wage variation bear directly on the issue of whether aggregate wages are procyclical or not. In particular, the participation effect works counter to a normal cyclical variation of aggregate wages - decreases in participation can lead to aggregate wage increases when there is essentially no change in individual wage levels or distribution. We now turn to an analysis of British wages that shows these features.

Our microeconomic data is again taken from the UK Family Expenditure Survey (FES) for the years 1978 to 1996. The FES is a repeated continuous cross-section survey which contains consistently defined micro data on wages, hours of work, employment status and education for each year since 1978. Our sample consists of all men aged between 19 and 59 (inclusive). ${ }^{41}$ The participating group consists of employees; the non-participating group includes individuals categorized as searching for work as well as the unoccupied. The hours measure for employees in FES is defined as usual weekly hours including

\footnotetext{
${ }^{41}$ We exclude individuals classified as self-employed. This could introduce some composition bias, given that a significant number of workers moved into self employment in the 1980s. However, given that we have no data on hours and relatively poor data on earnings for this group, there is little alternative but to exclude them. They are also typically excluded in aggregate figures.
} 
usual overtime hours, and weekly earnings includes overtime pay. We divide nominal weekly earnings by weekly hours to construct an hourly wage measure, which is deflated by the quarterly UK retail price index to obtain real hourly wages.

Individual attributes include education level and cohort effects. Individuals are classified into three educational groups; those who left full-time education at age 16 or lower, those who left aged 17 or 18, and those who left aged 19 or over. Dummy variables capture effects of five date-of-birth cohorts (b.1919-34, b.1935-44, b.1945-54, b.1955-64 and b.1965-77). We include various trend variables to account for a common business cycle effect. Finally, our measure of benefit income (income at zero-hours) is constructed for each individual as described in Blundell, Reed and Stoker (2003). After making the sample selections described above, our sample contains 40, 988 observations, of which 33,658 are employed, or $82.1 \%$ of the total sample.

\subsubsection{Real Wages and Employment}

Figure 8 shows log average wages in Britain from 1978 to 1996. These show a strong trend increase over the whole period. The trend appears for more disaggregate groups. Blundell, Reed and Stoker (2003) present a more detailed breakdown by cohort, region and education group, and show that the trend holds widely, including for the least educated group.

Figure 9 shows the overall male labor employment rate for the same period. Clearly there has been a large fall in the participation rate of men. Figure ?? presents the employment rate for those with low education. For this group there is a continued and much steeper decline in employment. This period also included two deep recessions in which there have been large fluctuations in male employment.

Considering Figures 8-10 together, one can understand the basic importance of sorting out wage growth at the individual level from changes in participation. The strong trend of aggregate wages is suggestive of great progress at increasing the well-being of laborers in general. ${ }^{42}$ However, great increases in unemployment are likely associated with unemployment of workers with lowest wages, or workers from the poorest groups. It is very important to understand how much of the upward trend in average wages is due to the elimination of low wage earners from employment.

\footnotetext{
${ }^{42}$ In fact, such a conclusion has been trumpeted by British newspapers.
} 


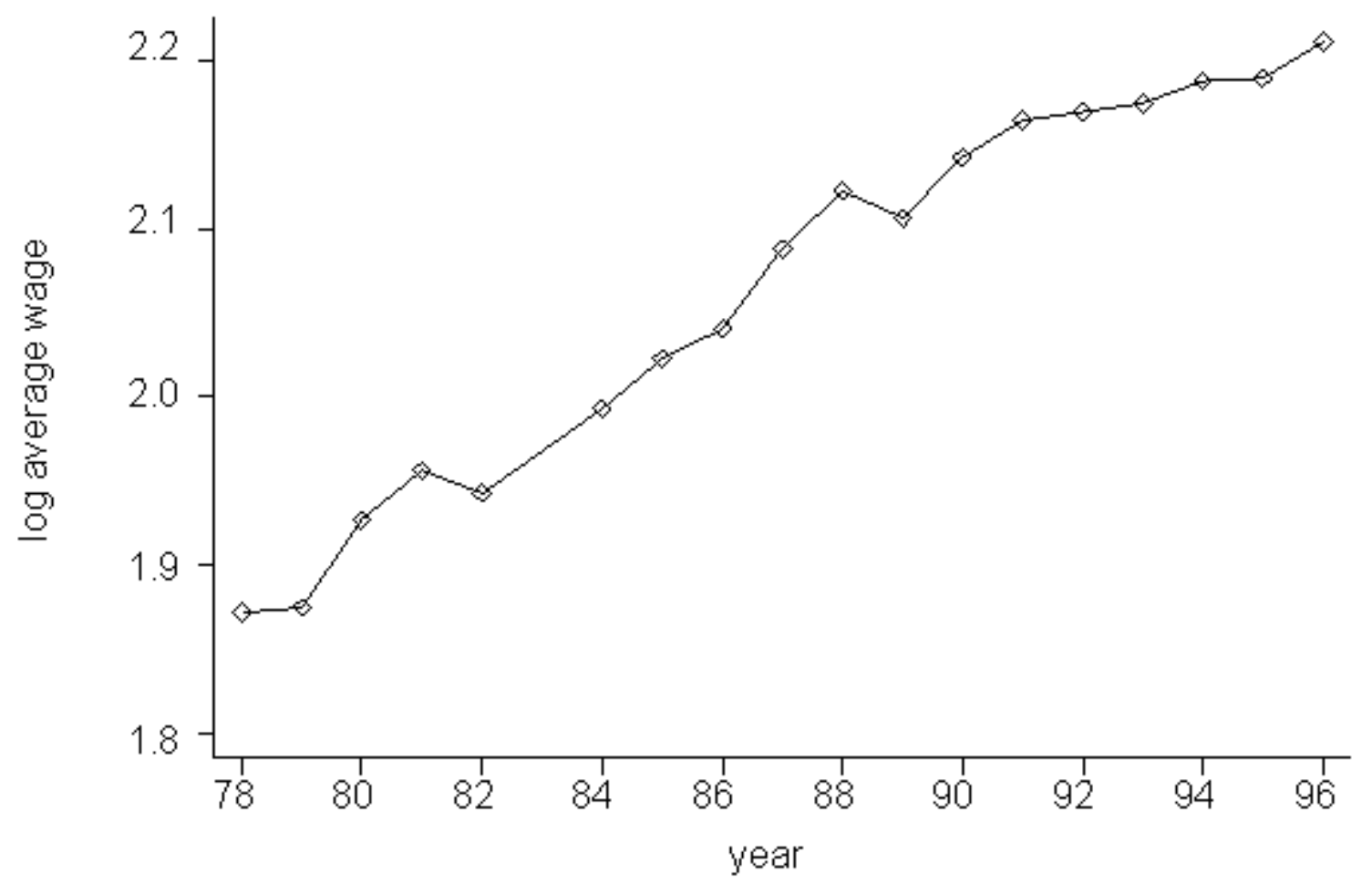

Figure 8: Male Hourly Wages 


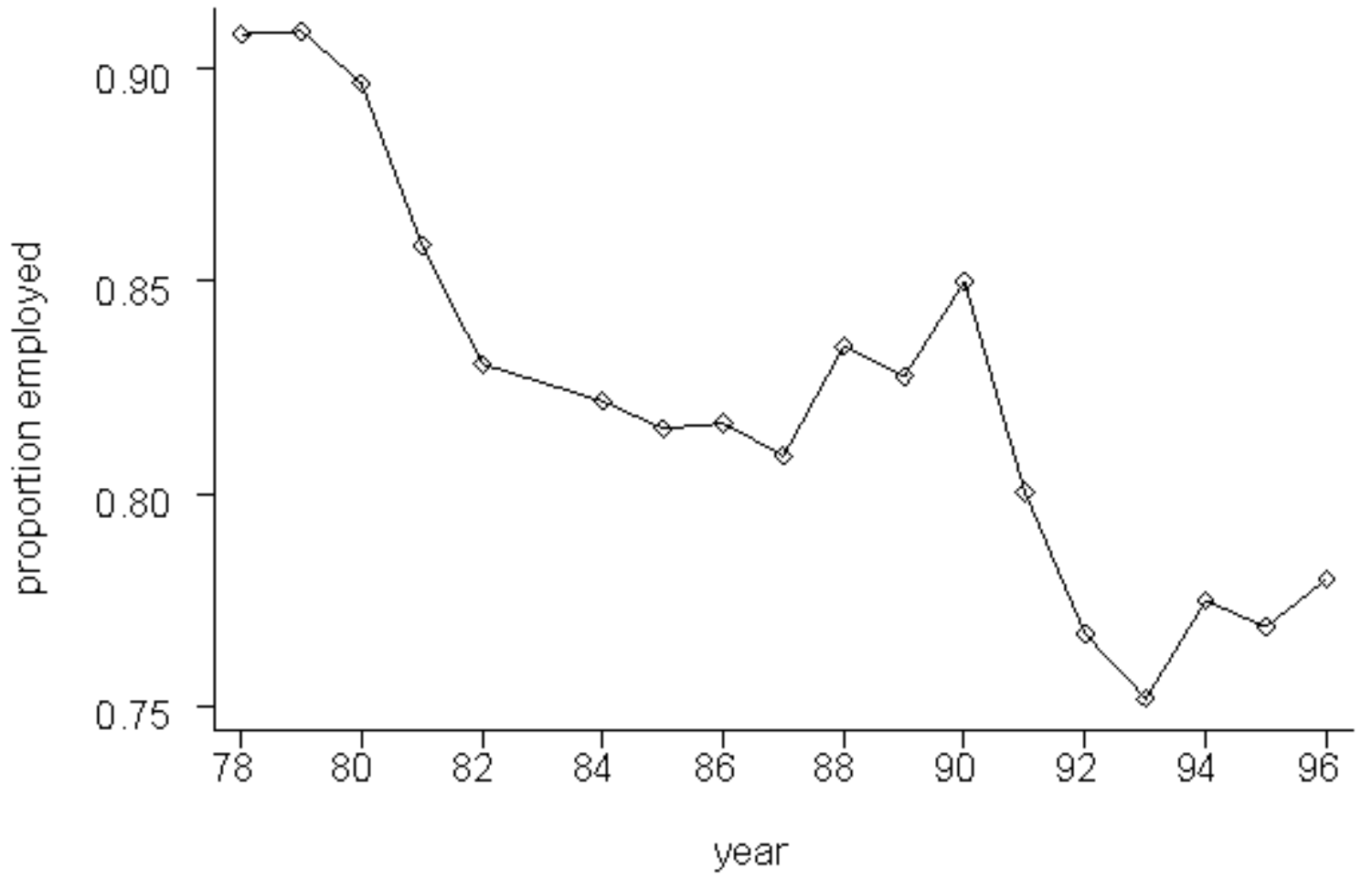

Figure 9: Male Employment Rate

There have also been well documented changes in real benefit income over time and across different groups of individuals. While it is unlikely that variation in real value of benefit income relative to real earnings can explain all of the variation in participation rates, the changes in real benefits act as an important "instrumental variable" for separating participation decisions from determinants of wages. Again, to the extent that changes in benefit income have discouraged (or encouraged) participation, it is essential to learn the size of this impact relative to the other factors driving changes in wages.

\subsubsection{Aggregation Results}

The Blundell, Reed and Stoker (2003) study considers a number of possible specifications for our individual level wage equations which relate to the various specifications. In the simplest of our 


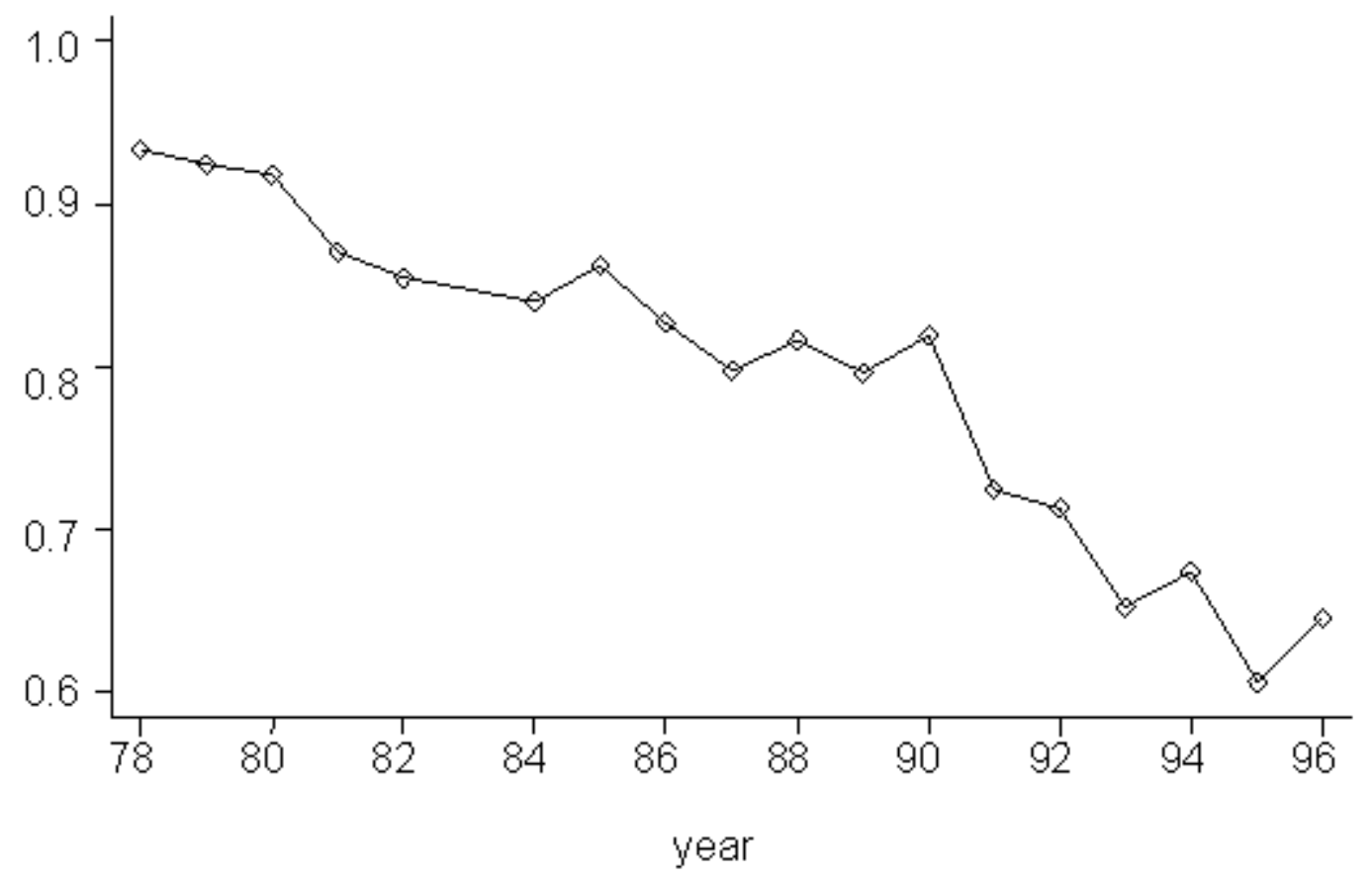

Figure 10: Employment Rate for the Low Educated 
specifications the full proportionality hypothesis is imposed on the (non-differentiated) human capital model, together with trend terms to reflect the business cycle effects on skill price. This specification was strongly rejected by the data. The preferred model had full interactions of cohort, trend, region, and education. These additional variables could reflect many differences in minimum educational standards across cohorts such as the systematic raising of the minimum school leaving age over the postwar period in the UK. The prices of different (education level) skills are allowed to evolve in different ways, by including an interaction between high education and the trend terms. These coefficients are marginally significant and show an increasing trend among groups with higher levels of human capital. The impact of adjusting for participation is very important. ${ }^{43}$ To see the impact of these results on aggregate wages, we turn to graphical analysis.

Figure 11 displays the (raw) log aggregate wage, the log aggregate wage minus the estimated aggregation bias terms, and the mean of the log wage from the selectivity adjusted micro model. We have plotted the return lines from a common point at the start of the time series rebased to zero for 1984, to highlight the changes in trend growth in wages indicated by our corrections. There is a clear downward shift in the trend, and an increased cyclical component in wage growth shown by both the corrected aggregate series and the estimated micro model.

This procedure is repeated for the lower education group in Blundell, Reed and Stoker (2003). Several features of this analysis are worth mentioning here. For instance, even the direction of movement of the uncorrected log aggregate wage does not always mirror that of the mean micro log wage. There is a reasonably close correspondence between the two in the 1984-88 period, but the 1990-1993 period is different. In 1990-1993, log aggregate wages are increasing, but the mean micro log wage (and the corrected aggregate wage) is decreasing - precisely the period where there is a big decline in participation. What is remarkable is that the aggregate data show reasonable growth in real wages, but such growth is virtually absent from the corrected series. We are left with a much more cyclical profile of wages.

If the model is exactly correct, the results from aggregating the selectivity-adjusted micro model

\footnotetext{
${ }^{43}$ Blundell, Reed and Stoker (2003) examined the impact of our normality assumptions by estimating with semiparametric methods. The estimated wage coefficients were hardly affected by this generalization.
} 


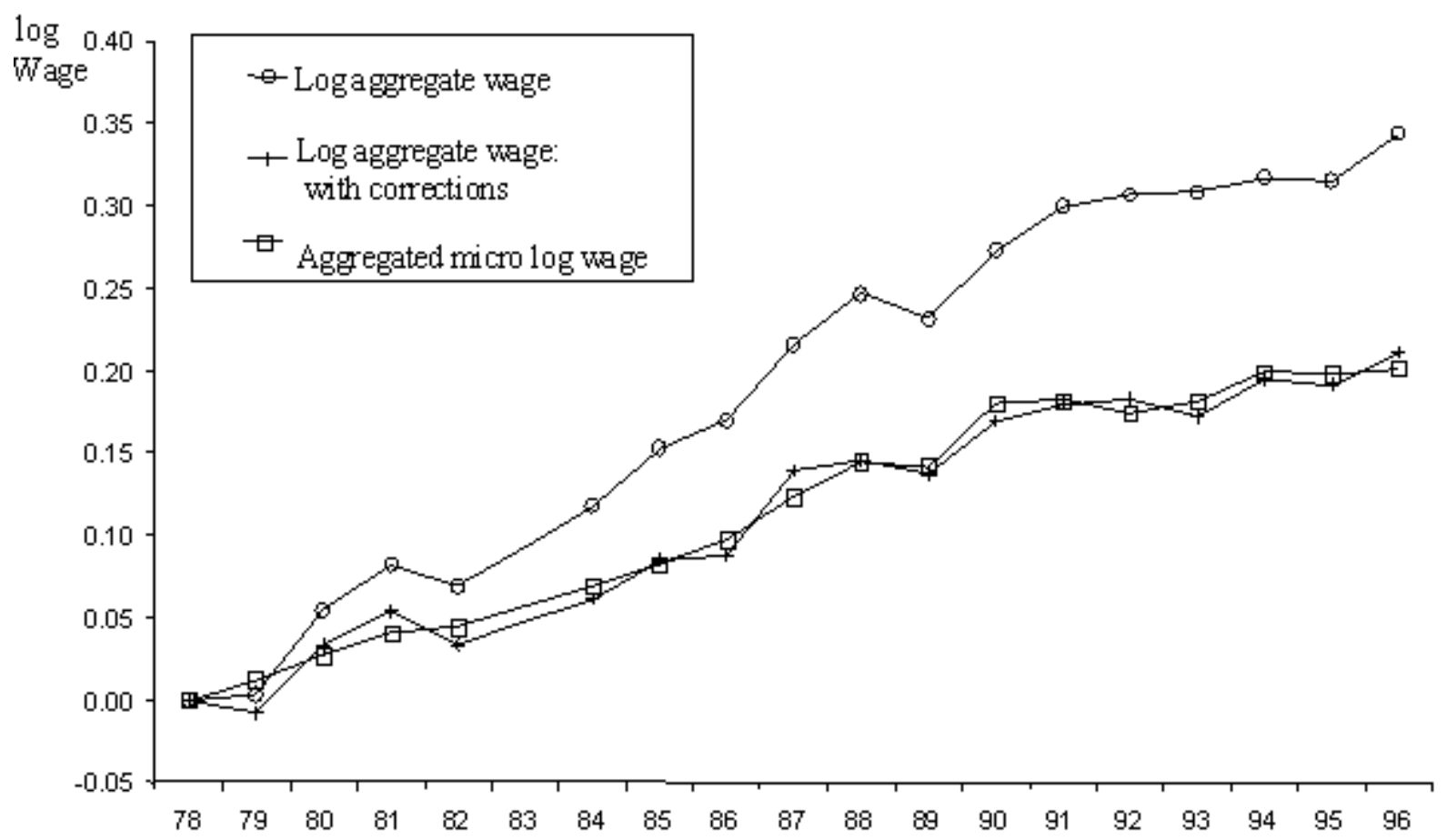

Figure 11: Hourly Wage Growth 
estimates should match the corrected aggregate series. They show a close correspondence in Figure 11, and a similar close correspondence is noted by Blundell, Reed and Stoker (2003) for more disaggregated groups. ${ }^{44}$ In any case, we view the correspondence between the corrected log aggregate micro wage and the mean micro log wage, as striking validation of the framework. This model specification, that provides a good and parsimonious specification of the evolution of log real wages, also seems to work well in terms of the specification of aggregation factors.

\section{Conclusion}

Macroeconomics is one of the most important fields of economics. It has perhaps the grandest goal of all economic study, which is to advise policymakers who are trying to improve the economic well-being of entire populations of people. In the mid-twentieth century, say from 1940-1970, macroeconomics had an orientation toward its role much like an oracle giving advice while peering down from the top of a mountain. That is, while economists could see people making detailed decisions about buying products, investing their wealth, choosing jobs or career paths, etc., macroeconomic models were extremely simple. For instance, describing the aggregate consumption of an entire economy could be done with taking into account just a few variables; aggregate income, lagged aggregate consumption, etc. Such equations often fit aggregate data extremely well. Unfortunately, such models could not predict future aggregate variables with sufficient precision to dictate optimal policies. Even with great statistical fit, there was too much uncertainty as to what the underlying processes were that drove the aggregate data, and for policy prescriptions, it is crucial to know something about those processes. ${ }^{45}$

What economists could get a handle on was how rational individuals and firms would behave in var-

\footnotetext{
${ }^{44}$ To get an idea of the precision of these results, Blundell, Reed and Stoker (2003) present bootstrap 95\% confidence bands for the corrected log wage estimates for various groups. These plots show that the micro model prediction and the corrections to the log aggregate wage are both quite tightly estimated. In all cases the micro model prediction and the corrections to the aggregate wage plot are significantly different from the raw aggregate wage measure and not significantly different from each other. This gives us confidence that we have identified compositional biases in the measured real wage with a reasonable degree of precision.

${ }^{45}$ There are many stories told in the economics profession about what giants of our field thought were the greatest contributions to social science. In this spirit, we relate the following. In the mid-1980's, one of the authors asked Paul Samuelson what he felt was the greatest failure in economics. Without hesitation, his answer was "macroeconomics and econometrics." The reason for this is that there had been an enormous anticipation in the 40's, 50's and 60's that simple empirical macroeconomic models would, in fact, be accurate enough to allow real economies to be guided and controlled, much like an automobile or a spacecraft. That this turned out to not be possible was a source of great disappointment.
} 
ious economic environments. Problems like how to allocate one's budget, how much to save and invest, or whether to work hard or not so hard, are sufficiently familiar that their essence could be captured with some mathematics, and economists could describe and prescribe optimal reactions. Economists could settle how someone being really smart and clear-headed would behave. Notwithstanding the anomalies pointed out recently by behavioral economists, the predictive power of economics rests on the notion that people facing a familiar situation will behave in their interests. Foolish, self-destructive or purely random behavior will not be repeated once it is consciously seen to be less good than another course. The transformation of economic analysis by mathematics occurred through the systematic understanding of rational and learning behavior by individuals and firms, and the overall implications of that for market interactions.

The merging of these two bodies of thought - macroeconomics and optimal behavior of individuals - is among the greatest development of economics in the last half century. This advance has been recognized by Nobel prizes to Lucas, Kydland and Prescott, and one should expect more prizes to be awarded to other important developers. Previous "schools of thought" have been replaced by groups differentiated by how they settle the tradeoff between realism and strict adherence to optimal economic behavior. The specification of macroeconomic models, the judgment of whether they are sensible, and the understanding of the impacts of economic policy, is now more systematic because of its embedding in the rules of optimal individual behavior.

The trouble is, this embedding cannot be right without taking account of aggregation. A oneperson or five-person economy is just not realistic. You can simulate a model with a few actors and pretend that it is realistic, but there is nothing in casual observation or empirical data or economic theory that suggests that such a stance is valid. There is much to be learned from rational individual behavior, but there must be a explicit bridge to economic aggregates because real people and their situations are so very heterogeneous. Aggregation is essential, because heterogeneity is a pervasive and indisputable fact of life.

In this paper, we have covered recent work on aggregation problems in a style that we hope is useful to empirical economists. Our orientation has been to highlight the importance of different types of individual heterogeneity; in particular, heterogeneity in tastes and reaction, heterogeneity in market 
participation, and heterogeneity in uninsurable risks. Our approach has been practical; we have covered recent advances in econometric modeling that address issues in aggregation, by considering explicit models at the individual level and among economic aggregates.

We have covered a wide range of ideas. First, we have detailed the main approach for incorporating distributional information into aggregate relationships, namely exact aggregation models, in the context of how that approach has been applied to the analysis of consumer demands. Second, we have shown how one can incorporate basic nonlinearity, insurance and dynamic elements, in our coverage of aggregate consumption based on CRRA preferences. Third, we have shown how to account for compositional heterogeneity, in our coverage of labor participation and wages. The latter two topics required explicit assumptions on the distribution of individual heterogeneity, and we have based our solutions on normal and lognormal assumptions on individual heterogeneity. While these distributional restrictions are specific, they do permit explicit formulations of the aggregate relationships of interest to be derived, and those formulations capture both location and spread (mean and variance) of the underlying elements of individual heterogeneity. We view our solutions in these cases as representative and clear, and good starting points for empirical modeling in the respective areas.

Whether one dates the beginning of the study of aggregation problems from the 1940's, 1930's or perhaps earlier, one can at best describe progress toward solutions as slow. Aggregation problems are among the most difficult problems faced in either the theoretical or empirical study of economics. Heterogeneity across individuals is extremely extensive and its impact is not obviously simplified or lessened by the existence of economic interaction via markets or other institutions. The conditions under which one can ignore a great deal of the evidence of individual heterogeneity are so severe as to make them patently unrealistic. With reference to our Introduction, as annoyances go, aggregation problems are particularly cloying. There is no quick, easy or obvious fix to dealing with aggregation problems in general.

Yet we see the situation as hopeful and changing, and offer the solutions discussed in this paper as evidence of that change. The sources of this change are two-fold, and it is worth pointing them out as well as pointing out how both are necessary.

The first source of change is the increasing availability of data on individuals observed over sequential 
time periods. To address questions of what kinds of individual heterogeneity are important for aggregate relationships, one must assess what kinds of heterogeneity are relevant to individual behavior for the problem at hand, and assess how much the distributions of the relevant heterogeneity vary over time. To the extent that this heterogeneity reflects differences in unexpected shocks to individual agents, the mechanisms that are available to individuals to insure against such shocks will have a strong bearing on the form of the aggregate relationship.

While we have advanced the idea of using aggregation factors (derived from time series of individual data) to summarize the impacts of aggregation, the specific method one uses is less important than the ability to use all available types of information to study economic relationships. That is, it is important to study any relationship among economic aggregates with individual data as well as aggregate data, to get as complete a picture as possible of the underlying structure. Even though modeling assumptions will always be necessary to develop explicit formulations of aggregate relationships, testing those assumptions is extremely important, and is not possible without extensive individual data over sequential time periods. Our view is that the prospects for meaningful advance continue to brighten, as the data situation with regard to individual behavior and aggregate economic variables will continue to improve.

The second source of change in studying aggregation problems is the recent, rapid rise in computing power. Realistic accommodation of individual heterogeneity typically requires extensive behavioral models, let alone combinations of individual models with aggregate relationships. Within the last twenty five years (or the professional lives of both authors), there has been dramatic changes in the ability to implement realistic models. Before this, it was extremely difficult to implement models that are necessary for understanding impacts of individual heterogeneity in aggregation.

Aggregation problems remain among the most vexing in all of applied economics. While they have not become less difficult in the past decade, it has become possible to study aggregation problems in a meaningful way. As such, there are many reasons to be optimistic about the prospects for steady progress on aggregation problems in the future. The practice of ignoring or closeting aggregation problems as "just too hard" is no longer appropriate. 


\section{References}

[1] Aigner, Dennis J. and Goldfeld, Stephen M. (1974), "Estimation and Prediction from Aggregate Data When Aggregates are Measured More Accurately that Their Components," Econometrica, 42, 113-34.

[2] Alessie, R. Devereux, M. and Weber, G. (1997), "Intertemporal consumption, durables and liquidity constraints: a cohort analysis", European Economic Review, 41. 37-60.

[3] Alessie, R., B. Melenberg and G. Weber (1988), "Consumption, leisure and earnings-related liquidity constraints: a note", Economics Letters, 27, 101-104.

[4] Allenby, Greg M. and Rossi, Peter E. (1991), "There is No Aggregation Bias: Why Macro Logit Models Work," Journal of Economic and Business Statistics, 9, 1-14.

[5] Atkeson, A. and M. Ogaki (1996), "Wealth-Varying Intertemporal Elasticities of Substitution: Evidence from Panel and Aggregate Data," Journal of Monetary Economics, 38, 507-534.

[6] Atkinson, A.B., J. Gomulka, and N. H. Stern (1990), "Spending on Alcohol: Evidence from the Family Expenditure Survey 1970-1983", Economic Journal, 100, 808-827.

[7] Aiyagari, S.R. (1994), "Uninsured Idiosyncratic Risk and Aggregate Savings", Quarterly Journal of Economics, 104(2), 219-240.

[8] Aiyagari, S.R. (1994), "Co-existence of a Representative Agent Type Equilibrium with a Non representative Agent Type Equilibrium", Journal of Economic Theory, 57(1), 230-36.

[9] Attanasio, O.P. (1999), "Consumption", in John B. Taylor and Michael Woodford, (eds.)., Handbook of Macroeconomics. (Amsterdam:North Holland).

[10] Attanasio, O.P. and M. Browning (1995), "Consumption Over the Life cycle and Over the Business Cycle", American Economic Review, 85(5), 1118-1137.

[11] Attanasio, O.P. and S.J. David (1996), "Relative Wage Movements and the Distribution of Consumption", Journal of Political Economy, 104, 1227-1262.

[12] Attanasio, O.P. and P.K. Goldberg (1997), "On the Relevance of Borrowing Restrictions. Evidence from Car Loans in the US", in progress.

[13] Attanasio, O.P. and G. Weber (1993a), "Is Consumption Growth Consistent with Intertemporal Optimization? Evidence from the Consumer Expenditure Survey", Journal of Political Economy, 103(6), 1121-1157. 
[14] Attanasio, O.P. and G. Weber (1993b), "Consumption Growth, the Interest Rate and Aggregation", Review of Economic Studies, 60, 631-49.

[15] Anderson, Simon P.; de Palma, Andrw and Thisse, Jacques-Francios (1989), "Demand for Differentiated Products, Discrete Choice Models and the Characteristics Approach," Review of Economic Studies, 56, 21-36.

[16] Barker, Terence S. and Pesaran, M. Hashem (1990), Disaggregation in Econometric Modeling, London, Routledge.

[17] Barnett, William A. (1979), "Theoretical Foundations of the Rotterdam Model," Review of Economic Studies, 46, 109-130.

[18] Barten A.P. (1964), "Family Composition, Prices and Expenditure Patterns", in

[19] P.E. Hart, F. Mills and J.K. Whitaker (eds.), "Econometric Analysis for National

[20] Economic Planning". London: Butterworths.

[21] Banks, J. Blundell, R.W. and Lewbel, A. (1997), "Quadratic Engel Curves, Indirect Tax Reform and Welfare Measurement", Review of Economics and Statistics, LXXIX, 4, 527-539.

[22] Banks, J. Blundell, R.W. and Tanner, S, (1998) "Is There a Retirement-Savings Puzzle?", American Economic Review, Vol. 88, No.4. 769-788, September.

[23] Banks, J., Blundell, R. and A. Brugiavini (2001), "Risk Pooling, Precautionary Saving and Consumption Growth", Review of Economic Studies, Vol. 68(4) No.237, 757-779.

[24] Bean, C.R. (1986), "The Estimation of 'Surprise' models and the 'Surprise' consumption Function", Review of Economic Studies, 53, 497-516.

[25] Beaudry, Paul and David Green (1996), "Cohort Patterns in Canadian Earnings and the SkillBased Technical Change Hypothesis," Working Paper, Department of Economics, University of British Columbia.

[26] Berndt, Ernst R.; Darrough, Masako N. and Diewert W. Erwin (1977), "Flexible Functional Forms and Expenditure Distributions: An Application to Canadian Consumer Demand Functions," International Economic Review, 18, 651-675.

[27] Becker, Gary S. (1962), "Irrational Behavior and Economic Theory," Journal of Political Economy, 70, 1-13.

[28] Bewley, T. (1977),"The Permanent Income Hypothesis: a Theoretical Formulation", Journal of Economic Theory, 16, 252-92. 
[29] Bierens, H.J. and Pott-Buter H.A. (1990) "Specification of household Engel curves by nonparametric regression", Econometric Reviews, 9, 123-184.

[30] Blackorby, Charles; Boyce, Richard and Russell, Robert R. (1978), "Estimation of Demand Systems Generated by the Gorman Polar Form: A Generalization of the S-Branch Utility Tree," Econometrica, 46, 345-364.

[31] Blackorby, Charles; Primont, Daniel and Russell, Robert R. (1978), Duality, Separability and Functional Structure: Theory and Economic Applications, Amsterdam, North Holland.

[32] Blinder, Alan S. (1975), "Distribution Effects and the Aggregate Consumption Function," Journal of Political Economy, 83, 447-75.

[33] Bils, Mark J. (1985), "Real Wages Over the Business Cycle: Evidence from Panel Data," Journal of Political Economy, 93, 666-689.

[34] Blundell, R. W., (1988), "Consumer Behaviour: Theory and Empirical Evidence", Economic Journal, 98, 16-65.

[35] Blundell, R. W., Browning, M. and I. Crawford (2003), "Nonparametric Engel Curves and Revealed Preference", Econometrica, Vol.71, No.1, 205-240, January.

[36] Blundell, R., M. Browning and C. Meghir (1994), "Consumer Demand and Life-Cycle Allocation of Household Expenditures," Review of Economic Studies, 61, 57-80.

[37] Blundell, R., A. Duncan and K. Pendakur (1998), "Semiparametric Estimation and Consumer Demand," Journal of Applied Econometrics, 13, 435-461.

[38] Blundell, R.W., Ham, J. and Meghir, C. (1987), "Unemployment and Female Labour Supply", Economic Journal, 97,44-64.

[39] Blundell, R. and T. MaCurdy (1999), "Labor supply: A Survey", in Handbook of Labor Economics vol III(a), ed. By O. Ashenfelter and D. Card (North Holland:Amsterdam).

[40] Blundell, R., L. Pistaferri and I. Preston (2003), "Consumption Inequality and Partial Insurance", UCL Discussion Paper, 03/06, October..

[41] Blundell, R. W., Pashardes, P. and Weber, G. (1993), "What do we learn about consumer demand patterns from micro-data?", American Economic Review, June.

[42] Blundell, R.W and I. Preston (1998), "Income Uncertainty and Consumption Inequality", Quarterly Journal of Economics, May.

[43] Blundell, R.W., H. Reed and T. Stoker (2003) "Interpreting Aggregate Wage Growth", American Economic Review, Vol.93, No.4, 1114-1131, September. 
[44] Blundell, R. and J-M Robin (1999) "Estimation in Large and Dissaggregated Demand Systems: An Estimator for Conditionally Linear Systems", Journal of Applied Econometrics, Vol.14, No.3, May-June, 209-232.

[45] Blundell, R. and J-M Robin (2000), "Latent Separability: Grouping Goods without weak Separability", Econometrica, Vol.68, No.1, 53-84.

[46] Blundell, R. and T. Stoker (1999) "Consumption and the Timing of Income Risk", European Economic Review, 43(3), March, 475-507.

[47] Blundell, R. and T. Stoker (2003), "Models of Aggregate Economic Relationships that Account for Heterogeneity," manuscript, December.

[48] Brown, Donald J. and Matzkin, Rosa L. 1996. "Testable Restrictions on the Equilibrium Manifold," Econometrica, 64(6), 1249-1262.

[49] Browning, Martin (1992), "Children and Household Economic Behavior," Journal of Economic Literature, 30, 1434-1475.

[50] Browning, Martin (1993), "Estimating Micro Parameters from Macro Data Alone: Some Pessimistic Evidence," Research in Economics, 47, 253-268.

[51] Browning, M.J. and Meghir, C. (1991), "The effects of male and female labour supply on commodity demands", Econometrica, 59, 925-951.

[52] Browning, M. and A. Lusardi (1996), "Household Saving: Micro Theories and Micro Facts", Journal of Economic Literature, 34(4), 1797-1855.

[53] Browning, M., L. Hansen and J.J. Heckman (1999), "Micro Data and General Equilibrium Models," in J. Taylor and M. Woodford (eds), Handbook of Macroeconomics, Amsterdam: Elsevier. 1999, Chapter 8, 543-633.

[54] Buse, Adolph (1992). "Aggregation, Distribution and Dynamics in the Linear and Quadratic Expenditure Systems," Review of Economics and Statistics, 74, 45-53.

[55] Caballero, R.J. (1990), "Consumption Puzzles and Precautionary Savings," Journal of Monetary Economics, 25, January, 113-36.

[56] Caballero, Ricardo J. and Engel, Eduardo M.R.A. (1991), "Dynamic (S,s) Economies," Econometrica, 59, 1659-1686.

[57] Caballero, Ricardo J. and Engel, Eduardo M.R.A. (1992), "Microeconomic Adjustment Hazards and Aggregate Demands," MIT Department of Economics. 
[58] Cameron, A. Colin (1990), "Aggregation in Discrete Choice Models: An Illustration of Nonlinear Aggregation," in T.S. Barker and M.H. Pesaran, eds., Disaggregation in Econometric Modeling, London, Routledge.

[59] Caplin, Andrew S. and Nalebuff, Barry (1991), "Aggregation and Imperfect Competition: On the Existence of Equilibrium," Econometrica, 59, 1-24.

[60] Caplin, Andrew S. and Spulber, Daniel (1987), "Menu Costs and the Neutrality of Money," Quarterly Journal of Economics, 102, 703-726.

[61] Carroll, Christoper D. (2000), "Requiem for the Representative Consumer? Aggregate Implications of Microeconomic Consumption Behavior," American Economic Review Papers and Proceedings, 90, 110-115.

[62] Chiappori, Pierre-Andre (1988), "Rational Household Labor Supply," Econometrica, 56, 63-90.

[63] Chiappori, Pierre-Andre. 1994. "The Collective Approach to Household Behaviour", in The Measurement of Household Welfare, R. Blundell, I. Preston and I. Walker, eds., Cambridge: Cambridge University Press, 70-86.

[64] Chetty, V.K. and Heckman, James J. (1986), "A Dynamic Model of Aggregate Output Supply, Factor Demand and Entry and Exit for a Competitive Industry with Heterogeneous Plants," Journal of Econometrics, 33, 237-262.

[65] Cochrane, J.H. (1991), "A Simple Test of Consumption Insurance", Journal of Political Economy , 99, 957-976.

[66] Cogan, J.F. (1981), "Fixed Costs and Labor Supply", Econometrica, 49, 945-964.

[67] Cowing, Thomas G. and McFadden, Daniel L. (1984), Microeconomic Modeling and Policy Analysis, New York, Academic Press.

[68] Deaton, Angus S. (1985), "Panel Data from Time Series of Cross Sections," Journal of Econometrics, 30. 109-126.

[69] Deaton, Angus S.(1991), "Savings and Liquidity Constraints", Econometrica, 59, 1221-48.

[70] Deaton, Angus S.(1993), Understanding Consumption, Oxford University Press, Oxford.

[71] Deaton, Angus S. and Muellbauer, John (1980a), "An Almost Ideal Demand System," American Economic Review, 70, 312-326.

[72] Deaton, Angus S. and Muellbauer, John (1980b), Economics and Consumer Behavior, Cambridge, Cambridge University Press. 
[73] Deaton, A. and C. Paxson (1994), "Intertemporal Choice and Inequality," Journal of Political Economy, 102, 4437-467.

[74] Debreu, Gerard (1974), "Excess Demand Functions," Journal of Mathematical Economics, 1, $15-23$.

[75] Dickens, R. (1996), "The Evolution of Individual Male earnings in Great Britain, 1975-1994", CEP Discussion Paper No. 306, November.

[76] Diewert, W. Erwin (1977), "Generalized Slutsky Conditions for Aggregate Demand Functions, Journal of Economic Theory, 15, 353-362.

[77] Dumas, Bernard (1989), "Two-Person Dynamic Equilibrium in the Capital Market," The Review of Financial Studies, 2, 159-188.

[78] Dynan, K.E. (1993), "How prudent are Consumers?", Journal of Political Economy, 101, 11041113.

[79] Epstein, L.G. and S.E. Zin (1989), "Substitution, Risk Aversion and the Temporal Behaviour of Consumption and Asset Returns: A Theoretical Framework", Econometrica, 57(4), 937-969.

[80] Epstein, L.G. and S.E. Zin (1991), "Substitution Risk Aversion and the Temporal Behaviour of Consumption and Asset Returns: An Empirical Analysis", Journal of Political Economy, 99(2), 263-286.

[81] Fair, Ray C. and Dominguez, Katherine M. (1991), "Effects of the Changing U.S. Age Distribution on Macroeconomic Equations," American Economic Review, 81, 1276-1294.

[82] Feenberg, Daniel R. and Rosen, Harvey S. (1983), "Alternative Tax Treatment of the Family: Simulation Methodology and Results," Chapter 1 of M.S. Feldstein, ed., Behavioral Simulation Methods in Tax Policy Analysis, Chicago, University of Chicago Press.

[83] Freixas, Xavier and Mas-Colell, Andreu (1987), "Engel Curves Leading to the Weak Axiom in the Aggregate," Econometrica, 55, 515-532.

[84] Forni, Mario and Marco Lippi (1997), Aggregation and the Microfoundations of Dynamic Macroeconomics, Oxford, Clarendon Press.

[85] Garcia, R, A. Lusardi and S. Ng (1997) "Excess Sensitivity and Asymmetries in Consumption" Journal of Money Credit and Banking, 29, 154-176.

[86] Grandmont, Jean-Michel (1992), "Transformations of the Commodity Space: Behavioral Heterogeneity and the Aggregation Problem," Journal of Economic Theory, 57, 1-35. 
[87] Granger, Clive W.F. (1980), "Long-Memory Relationships and the Aggregation of Dynamic Models," Journal of Econometrics, 14, 227-38.

[88] Granger, Clive W.F. (1987), "Implications of Aggregation with Common Factors," Econometric Theory, 3, 208-222.

[89] Granger, Clive W.F.(1990), "Aggregation of Time Series Variables: A Survey," in Barker, Terence S. and Pesaran, M. Hashem, eds., Disaggregation in Econometric Modeling, London, Routledge.

[90] Goodfriend, M. (1992), "Information Aggregation Bias", American Economic Review, 82, 508519.

[91] Gorman, William M. (Terence) (1953), "Community Preference Fields," Econometrica, 21, 63-80.

[92] Gorman, William M. (Terence) (1981), "Some Engel Curves," in Deaton, Angus S., ed. Essays in the Theory and Measurement of Consumer Behavior, Cambridge, Cambridge University Press.

[93] Gosling, Amanda, Machin, Stephen and Meghir, Costas. (2000) "The Changing Distribution of Male Wages in the UK, 1966-93" Review of Economic Studies, Vol 67(4), pp. 635-666.

[94] Grunfeld, Yehuda and Griliches, Zvi (1960), "Is Aggregation Necessarily Bad?" Review of Economics and Statistics, 42, 1-13.

[95] Hall, Robert E. (1978), "Stochastic Implications of the Life Cycle-Permanent Income Hypothesis: Theory and Evidence," Journal of Political Economy, 86, 971-987.

[96] Hall, R.E. (1988), "Intertemporal Substitution in Consumption", Journal of Political Economy, 96(2), 339-357.

[97] Hansen, Gary D. (1985), "Indivisible Labor and the Business Cycle," Journal of Monetary Economics, 16, 309-27.

[98] Hansen, Lars Peter and Singleton, Kenneth J. (1983) "Stochastic Consumption, Risk Aversion and the Temporal Behavior of Asset Returns," Journal of Political Economy, 91, 249-65.

[99] Hansen, L.P. and K.J. Singleton (1982), "Generalized Instrumental Variables Estimation of Nonlinear Rational Expectations Models", Econometrica 50(5), 1269-1286.

[100] Hardle, Wolfgang; Hildenbrand, Werner and Jerison, Michael (1991), "Empirical Evidence for the Law of Demand," Econometrica, 59, 1525-1550.

[101] Hausman, J. A., W. K. Newey, H. Ichimura, and J. L. Powell (1991), "Identification and Estimation of Polynomial Errors in Variables Models", Journal of Econometrics, 50, 273-296. 
[102] Hausman, J.A., W.K. Newey and J.L. Powell (1994), "Nonlinear Errors-in-Variables: Estimation of Some Engel Curves," Journal of Econometrics, 65, 205-233.

[103] Hayashi, F. (1985), "The Effects of Liquidity Constraints on Consumption: A Cross Section Analysis", Quarterly Journal of Economics, 100, 183-206.

[104] Hayashi, F, (1987), "Tests for Liquidity Constraints: A Critical Survey", in Truman Bewley (ed.) Advances in Econometrics, Fifth World Congress, Vol.2 (Cambridge : Cambridge University Press).

[105] Hayashi, F., J. Altonji and L. Kotlikoff (1996), "Risk-Sharing between and within Families", Econometrica, 64, 261-294.

[106] Heaton, John and Lucas, Deborah (1996), "Evaluating the Effects of Incomplete Markets on Risk Sharing and Asset Pricing," Journal of Polictical Economy, 104, 443-87.

[107] Heckman, J.J. (1974), 'Effects of Child-Care Programs on Women's Work Effort', Journal of Polictical Economy, 82(2), S136-S163.

[108] Heckman, J.J. (1979), 'Sample Selection Bias as a Specification Error', Econometrica, 47, 153-161.

[109] Heckman, J.J. (1990), 'Varieties of Selection Bias', American Economic Review, 80(2), 313-318.

[110] Heckman, J.J. and B.E. Honore (1990), "The Empirical Content of the Roy Model," Econometrica, 58, 1121-1149.

[111] Heckman , J. and Sedlacek, G. (1990), "Self-Selection and the Distribution of Hourly Wages", Journal of Labor Economics, 8, S329-S363.

[112] Heckman, James, J. and Chetty, V.K. (1986), "A Dynamic Model of Aggregate Output, Factor Demand and Entry and Exit for a Competitive Industry with Heterogeneous Plants," Journal of Econometrics, 33, 237-262.

[113] Heckman, James J. and Sedlacek, Guilherme (1985), "Heterogeneity, Aggregation and Market Wage Functions: An Empirical Model of Self-Selection in the Labor Market," Journal of Political Economy, 93, 1077-1125.

[114] Heckman, James J. and Walker, James R. (1989), "Forecasting Aggregate Period-Specific Birth Rates: The Time Series Properties of a Microdynamic Neoclassical Model of Fertility," Journal of the American Statistical Association, 84, 958-965.

[115] Heckman, James J. and Walker, James R. (1990), "The Relationship Between Wages and Income and the Timing and Spacing of Births: Evidence from Swedish Longitudinal Data," Econometrica, $58,1411-1442$. 
[116] Heineke, John M. and Shefrin, Herschel M. (1990), "Aggregation and Identification in Consumer Demand Systems," Journal of Econometrics, 44, 377-390.

[117] Hicks, J. R. (1956), A Revision of Demand Theory, London: Oxford University Press.

[118] Hildenbrand, W.(1981), "Short Run Production Functions Based on Microdata," Econometrica, 49, 1095-1126.

[119] Hildenbrand, W.(1983), "On the Law of Demand," Econometrica, 51, 997-1019.

[120] Hildenbrand, W (1992), "Market Demand, Theory and Empirical Evidence," Discussion Paper A-359, Universitat Bonn.

[121] Hildenbrand, W. (1994), Market Demand: Theory and Empirical Evidence, Princeton: Princeton University Press.

[122] Hildenbrand, W. (1998), "How Relevant are Specifications of behavioural relations on the microlevel for modelling the time path of population aggregates?", European Economic Review, 42, 437-458.

[123] Hildenbrand, W. and A. Kneip (1993), "Family Expenditure Data, Heteroscedasticity and the law of Demand," Ricerche Economiche, 47, 137-165.

[124] Houthakker, Hendrick S. (1955), "The Pareto Distribution and the Cobb-Douglas Production Function in Activity Analysis," REStud,23, 27-31.

[125] Jappelli, Tullio (1990), "Who is Credit Constrained in the US Economy", Quarterly Journal of Economics, 104, 219-234.

[126] Jappelli, T. and M. Pagano (1994), "Saving, Growth and Liquidity Constraints", Quarterly Journal of Economics, 109, 83-110.

[127] Jappelli, T., J-S. Pischke and N. Souleles (1998), ”Testing for Liquidity Constraints using Complementary Data Sources", Review of Economics and Statistics.

[128] Johansen, Leif (1972), Production Functions, Amsterdam, North Holland.

[129] Joint Committee on Taxation (1992), Discussion of Revenue Estimation and Process, JCS 14-92, August 13, 1992, U.S. Government Printing Office, Washington, D.C.

[130] Jorgenson, Dale W.; Lau, Lawrence J. and Stoker, Thomas M. (1980), "Welfare Comparisons and Exact Aggregation," American Economic Review, 70, 268-272.

[131] Jorgenson, Dale W.; Lau, Lawrence J. and Stoker, Thomas M. (1982), "The Transcendental Logarithmic Model of Aggregate Consumer Behavior," in Basmann, Robert L. and Rhodes, George, eds., Advances in Econometrics, Vol. 1, Greenwich, JAI Press, 97-238. 
[132] Jorgenson, Dale W. and Slesnick, Daniel T. (1984), "Aggregate Consumer Behavior and the Measurement of Inequality," Review of Economic Studies, 51, 369-392.

[133] Jorgenson, Dale W. and Slesnick, Daniel T. (2005), "Consumer and Labor Supply," manuscript, January.

[134] Jorgenson, Dale W.; Slesnick, Daniel T. and Stoker, Thomas M. (1988), "Two Stage Budgeting and Exact Aggregation," Journal of Business and Economic Statistics, 6, 313-325.

[135] Jorgenson, Dale W. and Stoker, Thomas M. (1986), "Nonlinear Three Stage Least Squares Pooling of Cross Section and Average Time Series Data," in Moroney, John R., ed., Advances in Statistical Analysis and Statistical Computing, Vol. 1, Greenwich, JAI Press, 87-116.

[136] Katz, Lawrence F. and Kevin M. Murphy (1992), "Changes in Relative Wages, 1963-1987: Supply and Demand Factors," Quarterly Journal of Economics, 35-78.

[137] Kelejian, Harry J. (1980), "Aggregation and Disaggregation of Nonlinear Equations," in Jan Kmenta and James B. Ramsey, eds., Evaluation of Econometric Models, New York, Academic Press.

[138] Kirman, Alan P. (1992), "Whom or What Does the Representative Individual Represent," Journal of Economic Perspectives, 6, 117-136.

[139] Krussell, P. and A.A. Smith (1998), "Income and Wealth Heterogeneity in the Macroeconomy", Journal of Political Economy, October 1998.

[140] Lam, Pok-Sang (1992), "Permanent Income, Liquidity, and Adjustments of Automobile Stocks: Evidence from Panel Data," Quarterly Journal of Economics, 106, 203-230.

[141] Lau, Lawrence J. (1977), "Existence Conditions for Aggregate Demand Functions," Institute for Mathematical Studies in the Social Sciences, Stanford University, Technical Report No. 248.

[142] Lau, Lawrence J. (1982), “A Note on the Fundamental Theorem of Exact Aggregation,” Economic Letters, 9. 119-126.

[143] Lee, Lung-Fei and Robert H. Porter (1984), "Switching Regression Models with Imperfect Sample Separation: with an application to Cartel Stability", Econometrica, 52, 391-418.

[144] Lee, K.; Pesaran, M. Hashem and Pierse, Richard G. (1990), "Testing for Aggregation Bias in Linear Models," Economic Journal, 100, 137-150.

[145] Leser, Conrad E.V. (1963), "Forms of Engel Functions," Econometrica, 31, 694-703.

[146] Lewbel, A. (1989a), “A Demand System Rank Theorem,” Econometrica, 57, 701-706. 
[147] Lewbel, A. (1989b), "Exact Aggregation and a Representative Consumer," Quarterly Journal of Economics, 104, 622-33.

[148] Lewbel, A. (1990), "Income Distribution Movements and Aggregate Money Illusions," Journal of Econometrics, 43, 35-42.

[149] Lewbel, A. (1991), "The Rank of Demand Systems: Theory and Nonparametric Estimation," Econometrica, 59, 711-730.

[150] Lewbel, A. (1992), "Aggregation with Log-Linear Models", Review of Economic Studies, 59, 635-642.

[151] Lewbel, A. (1993), "Distributional Movements, Macroeconomic Regularities and the Representative Consumer," Research in Economics, 47, 189-199.

[152] Lewbel, Arthur (1994), "Aggregation and Simple Dynamics," American Economic Review, 84, 905-918.

[153] Lippi, Marco (1988), "On the Dynamic Shape of Aggregated Error Correction Models," Journal of Economic Dynamics and Control, 12, 561-585.

[154] Lusardi, Annamaria (1996), "Permanent Income, Current Income and consumption: Evidence from Two Panel Data Sets", Journal of Business and Economic Statistics, 14, 81-89.

[155] Mace, B.J. (1991), "Full Insurance in the Presence of Aggregate Uncertainty," Journal of Political Economy, 99, 928-956.

[156] MaCurdy, T.F. (1982), "The Use of Time Series Processes to Model the Error Structure of Earnings in a Longitudinal Data Analysis," Journal of Econometrics, 18, January, 83-114.

[157] MaCurdy, Thomas E. (1987), "A Framework for Relating Microeconomic and Macroeconomic Evidence on Intertemporal Substitution," in Bewley, Truman F., ed., Advances in Econometrics, Fifth World Congress, Vol. II, 149-176.

[158] Mankiw, N. Gregory and David N. Weil (1989), "The Baby Boom, the Baby Bust, and the Housing Market," Regional Science and Urban Economics, 19, 235-258.

[159] Marshak, Jacob (1939), "Personal and Collective Budget Functions," Review of Economic Statistics, 21, 161-170.

[160] McFadden, D. and F. Reid (1975), "Aggregate Travel Demand Forecasting from Disaggregated Behavioral Models," Transportation Research Record, No. 534.

[161] Meghir, C., and L. Pistaferri (2004), "Income variance dynamics and heterogeneity", Econometrica, 72(1), 1-32. 
[162] Meghir, C, and E Whitehouse (1996), 'The Evolution of Wages in the UK: Evidence from Micro Data', Journal of Labor Economics, 14(1), 1-25.

[163] Meghir, C. and G. Weber (1996), "Intertemporal Nonseparability or Borrowing Restrictions? A Disaggregate Analysis using a US Consumption Panel", Econometrica, 64(5), 1151-1181.

[164] Modigliani, Franco (1970), "The Life Cycle Hypothesis of Saving and Intercountry Differences in the Saving Ratio," in W. Eltis, M. Scott and I. Wolfe, eds. Induction, Growth and Trade, Oxford, Clarendon Press.

[165] Moffitt, Robert (1991), "Identification and Estimation of Dynamic Models with a Time Series of Repeated Cross Sections," Draft, Brown University.

[166] Muellbauer, John (1975), "Aggregation, Income Distribution and Consumer Demand," Review of Economic Studies, 42, 525-543.

[167] Muellbauer, John (1976), "Community Preferences and the Representative Consumer," Econometrica, 44, 979-1000.

[168] Muellbauer, John (1981), "Linear Aggregation in Neoclassical Labor Supply," Review of Economic Studies, 48, 21-36.

[169] Pesaran, M. Hashem; Pierce, Richard G. and Kumar, M.S. (1989), "Econometric Analysis of Aggregation in the Context of Linear Prediction Models," Econometrica, 57, 861-888.

[170] Pischke, Jorn-Steffen (1995), "Individual Income, Incomplete Information and Aggregate Consumption", Econometrica, 63, 805-840.

[171] Pollak, Robert A. (1985), "A Transactions Cost Approach to Families and Households," Journal of Economic Literature, 23, 581-608.

[172] Pollak R.A. and Wales T.J. (1981), "Demographic Variables in Demand Analysis", Econometrica 49, pp. 1533-1551.

[173] Ray R. (1983) "Measuring the Cost of Children: An Alternative Approach", Journal of Public Economics 22, pp. 89-102.

[174] Powell, James L. and Stoker, Thomas M. (1985), "Estimation of Complete Aggregation Structures," Journal of Econometrics, 30, 317-344.

[175] Powell, J.L. (1994), Estimation of Semi-Parametric Models, in Engle and McFadden (eds) Handbook of Econometics, Vol 4, Elsevier, Amsterdam, 1994.

[176] Prescott, Edward C. (1986), "Theory Ahead of Business Cycle Measurement," Quarterly Review, Federal Reserve Bank of Minneapolis, 10, 9-22. 
[177] Rubinstein, Mark, (1974), "An Aggregation Theorem for Securities Markets," Journal of Financial Economics, 1, 224-244.

[178] Runkle, David E. (1991), "Liquidity Constraints and the permanent Income Hypothesis: Evidence from Panel Data", Journal of Monetary Economics 27, 73-98.

[179] Roy, A.D. (1951), "Some Thoughts on the Distribution of Earnings", Oxford Economic Papers, $3,135-146$.

[180] Samuelson, Paul A. (1956), "Social Indifference Curves," Quarterly Journal of Economics, 73, $1-22$.

[181] Sato, Kazuo (1975), Production Functions and Aggregation, Amsterdam, North Holland.

[182] Scheinkman, J.A. and L. Weiss (1986), "Borrowing Constraints and Aggregate Economic Activity", Econometrica, 54(1), 23-45.

[183] Schafer, Wayne and Sonnenschein, Hugo (1982), "Market Demand and Excess Demand Functions," in Arrow, K.J. and M.D. Intriligator, eds, Handbook of Mathematical Ecoonomics, Vol. II, New York, North Holland.

[184] Skinner, J. (1988), "Risky Income. Life Cycle consumption and Precautionary Savings", Journal of Monetary Economics, 22, 237-255.

[185] Solon, G., Barksy, R. and J. Parker (1994), "Measuring the Cyclicality of Real Wages: How Important is composition Bias?", Quarterly Journal of Economics, 109(1), 1-26.

[186] Sonnenschein, Hugo (1972), "Market Excess Demand Functions," Econometrica, 40, 549-563.

[187] Stoker, Thomas M. (1978), "The Pooling of Cross Section and Average Time Series Data," draft, Harvard University.

[188] Stoker, Thomas M. (1982), "The Use of Cross Section Data to Characterize Macro Functions," Journal of the American Statistical Association, 77, 369-380.

[189] Stoker, Thomas M. (1984a), "Completeness, Distribution Restrictions and the Form of Aggregate Functions," Econometrica, 52, 887-907.

[190] Stoker, Thomas M. (1984b), "Exact Aggregation and Generalized Slutsky Conditions," Journal of Economic Theory, 33, 368-377.

[191] Stoker, Thomas M. (1985), "Aggregation, Structural Change and Cross Section Estimation," Journal of the American Statistical Association, 80, 720-729. 
[192] Stoker, Thomas M. (1986a), "Aggregation, Efficiency and Cross Section Regression,” Econometrica, 54, 177-188.

[193] Stoker, Thomas M. (1986b), "The Distributional Welfare Impacts of Rising Prices in the United States," American Economic Review, 76, 335-349.

[194] Stoker, Thomas M. (1986c), "Simple Tests of Distributional Effects on Macroeconomic Equations," Journal of Political Economy, 94, 763-795.

[195] Stoker, Thomas M. (1986d), "Consistent Estimation of Scaled Coefficients," Econometrica, 54, 1461-1482.

[196] Stoker, Thomas M. (1992), Lectures on Semiparametric Econometrics, CORE Lecture Series, Louvain-la-Neuve, CORE Foundation.Stoker,

[197] Stoker, Thomas M. (1993), "Empirical Approaches to the Problem of Aggregation over Individuals", Journal of Economic Literature, XXXI, 1827-1874.

[198] Theil, Henri (1954), Linear Aggregation of Economic Relations, Amsterdam, North Holland.

[199] Theil, Henri (1975), Theory and Measurement of Consumer Demand, Vol.1, Amsterdam, North Holland.

[200] Townsend, R.M. (1994), "Risk and Insurance in Village India", Econometrica, 62, 539-592.

[201] Van Daal, Jan and Merkies, Arnold H.Q.M. (1984), Aggregation in Economic Research, Dordrecht, D. Reidel.

[202] Weber, G. (1993), "Earnings Related Borrowing Restrictions: Empirical Evidence from a Pseudo panel for the UK", Annales d'Economie et de Statistique, 29, 157-173.

[203] de Wolff, Pieter (1941), "Income Elasticity of Demand, A Micro-Economic and a Macro-Economic Interpretation," Economic Journal, 51, 140-145.

[204] Working, Harold (1943), "Statistical Laws of Family Expenditure," Journal of the American Statistical Association, 38, 43-56.

[205] Zeldes, S.P. (1989), "Consumption and Liquidity Constraints: An Empirical Investigation", Journal of Political Economy, 97(2), 305-46.

[206] Zeldes, S.P. (1989b), "Optimal consumption with Stochastic Income", Quarterly Journal of Economics, 104, 275-298.

[207] Zellner, Arnold (1969), "On the Aggregation Problem, a New Approach to a Troublesome Problem," in Estimation and Risk Programming, Essays in Honor of Gerhard Tintner, Berlin, Springer. 